\title{
A Literature Review of Taxes in Cross-Border Supply Chain Modeling: Themes, Tax Types and New Trade-Offs
}

\author{
Dong Mu ${ }^{1}$, Huanyu Ren ${ }^{1, *}$ and Chao Wang ${ }^{2, * \mathbb{D}}$ \\ 1 School of Economics and Management, Beijing Jiaotong University, Beijing 100044, China; dmu@bjtu.edu.cn \\ 2 Research Base of Beijing Modern Manufacturing Development, College of Economics and Management, \\ Beijing University of Technology, Beijing 100124, China \\ * Correspondence: author: 19113044@bjtu.edu.cn (H.R.); cwang@bjut.edu.cn (C.W.)
}

check for updates

Citation: Mu, D.; Ren, H.; Wang, C. A Literature Review of Taxes in Cross-Border Supply Chain Modeling: Themes, Tax Types and New Trade-Offs. J. Theor. Appl. Electron. Commer. Res. 2022, 17, 20-46. https://doi.org/10.3390/ jtaer17010002

Academic Editor: Zorica

Bogdanović

Received: 4 October 2021

Accepted: 18 December 2021

Published: 23 December 2021

Publisher's Note: MDPI stays neutral with regard to jurisdictional claims in published maps and institutional affiliations.

Copyright: (C) 2021 by the authors. Licensee MDPI, Basel, Switzerland. This article is an open access article distributed under the terms and conditions of the Creative Commons Attribution (CC BY) license (https:// creativecommons.org/licenses/by/ $4.0 /)$.

\begin{abstract}
The e-commerce platforms have facilitated the information flow of cross-border supply chain (CBSC) and attracted a wide range of companies and individuals to participate in cross-border businesses. The tax costs associated with cross-border commodity flow have received unprecedented attention. However, there is a lack of common platforms between international tax planners and CBSC optimizers, and the impact of various tax policies on CBSC operations is still unclear. To fill this gap, this study presents a literature review to elaborate on the interface between taxes and CBSC operations. First, a literature collection approach is constructed, and 71 pertinent publications are identified. Then, a four-dimensional categorization consisting of supply chain themes, research methodologies, tax types, and illustration types was designed to classify and summarize the research content of the selected articles. The results show that (1) there are six main supply chain-related themes, i.e., the supply chain network, the distribution channel structure, product quantity and quality, production outsourcing, the procurement mode, and supply chain emissions, that are significantly affected by taxes. (2) Four types of taxes, including the corporate income tax (CIT), tariffs, environmental taxes and the value-added tax (VAT), have obvious impacts on CBSC operations. (3) Four mainstream methodologies, i.e., mathematical models, empirical models, conceptual models and simulation models, have been applied to explore the tax effects in CBSC modeling. (4) The tax-saving opportunities in CBSC operations mainly come from the following five areas: CIT rate gaps in different regions, special tax regulations such as the tax cross-credit principle and arm's length principle, regional trade agreements (RTAs), preferential tax policies and export VAT rebate policy. Finally, this research provides a framework to analyze the trade-offs between taxes and traditional CBSC modeling factors. The results can support enterprises in CBSC in dealing with the complex international tax policies.
\end{abstract}

Keywords: cross-border supply chain modeling; international tax; tax-effective supply chain; offshoring decision; transfer pricing

\section{Introduction}

Benefiting from the proliferation of e-commerce platforms and international logistics networks, the material and information flow in cross-border supply chains (CBSC) have been significantly enhanced [1,2]. A wide range of small- and medium-sized enterprises (SME) and individuals have been involved in cross-border transactions, and operating a CBSC has become one of the core competitive advantages for most companies in the current business environment [3].

However, the tax policies in different sovereigns bring new challenges to the operators of CBSC [4], especially for the SMEs with weak capital risk resistance. The resulting taxrelated costs will significantly affect the firms' performance and consumers' utility [5]. Therefore, the interface between CBSC operations and tax planning has aroused broad concern from the industry. For example, Deloitte launched a service named "tax aligned 
supply chain" to help its clients explore tax-savings opportunities from the perspective of supply chain design and management [6].

In practice, operating a tax-effective CBSC is not trivial. First, corporate income tax (CIT) rates vary across jurisdictions. Generally, regions with lower production costs tend to have higher CIT rates. According to Stef van Weeghel [7], the total amount of payable tax as a percentage of firms' pretax profits in South America reached 53.3\% on average in 2018, which is $14.9 \%$ higher than that in North America. This gives rise to new trade-offs between tax-saving benefits and production drawbacks [8]. Second, the value-added tax (VAT) export refund policies in different countries are inconsistent, which complicates a firm's cross-border transactions [9]. For example, unlike other countries, the Chinese government does not apply a zero VAT rate for exported products, and changes in the export VAT refund rate will directly affect the profits of Chinese exporters [10]. Third, trade protectionism and local frictions have increased the uncertainty of CBSC taxes, especially tariff costs [4]. To avoid tax risks, multinational firms (MNF), such as IKEA and Apple, choose to adjust their CBSC structure and reassess their current offshore production and global procurement strategies. Finally, regional trade agreements (RTAs) and the corresponding preferential tariff areas are undergoing significant changes. According to the WTO [11], in recent years, there has been a significant increase in the number and scope of RTAs, and the number of RTAs under negotiation has increased even more significantly. To enjoy the tax benefits delivered by RTAs, the production and procurement of MNFs must meet the corresponding rules of origin, which usually is costly for many firms.

As mentioned above, with the new changes in the international business environment, operators of CBSCs need to pay considerable attention to the impact of different taxes. Academia has widely recognized the necessity of incorporating tax effects into CBSC models. However, most of the existing articles focus on certain tax types or tax regulations, such as carbon taxes [12,13], VAT rebate policies [9], tax cross-crediting policies [14], and CIT rate gaps [15].

To the best of our knowledge, only the interdisciplinary research of Henkow and Norrman [6] synthesized the impact of different types of tax policies on CBSC operations. Specifically, they combined the cross-border logistics system descriptions (based on workshops and interviews) with the legal analysis (from professional tax planners) to apply the main principles of the tax system to the design of cross-border logistics solutions. Although their study provided significant practical insights, it does not address the theoretical models. Moreover, the application scenarios of their research results are limited, as they only analyzed the impact of tax policies from the perspective of cross-border logistics solutions. Other related literature (or theoretical) reviews, such as the research of Cohen and Lee [4] and Handfield et al. [16], focused on the impact of new changes in the current global trade environment, including COVID-19, tariffs, and trade wars on CBSC operations. Their study indicated the significant impact of tax policies on CBSC operations but did not provide a systematic analysis for different tax policies. The specific impact and action mechanisms of different tax policies on CBSC operations are still unclear.

To fill this gap, this paper aims to construct a common platform between international tax planners and CBSC optimizers and provides a theoretical framework to analyze the trade-offs between taxes and traditional CBSC modeling factors. A comprehensive and targeted literature review based on the content analysis method will answer the following four questions:

Q1: In which supply chain functional stage can tax-related issues affect CBSC operations? The answer to this question will be given in Section 3.2.

Q2: What research methodologies and illustration methods are adopted to explore tax effects in CBSC modeling? The answer will be given in Section 3.3.

Q3: Which types of taxes have a significant impact on CBSC operations? The answer to this question will be given in Section 3.4. 
Q4: What tax-saving opportunities and new trade-offs do international tax regulations provide for CBSC operations? The answer to this question will be given in Sections 4.1 and 4.4 .

It is necessary to state that taxation is a professional issue, often demonstrated in legal frameworks, customs regulations, international taxation agreements, or articles in professional publications. To clarify the implementation approaches of different tax policies and the tax rate principles, this study does refer to the materials mentioned above, such as the global tax report released by Pricewaterhouse Coopers [7] and the database of global RTAs published by WTO [11]. Nevertheless, the scope of this review is restricted to the academic articles in the Web of Science database (WoS) because the core topic of this study is to analyze the impact of taxes on CBSC theoretical models. This boundary on the sample articles can help us focus on the intrinsic relationship between various tax policies and CBSC operations.

The remainder of this paper is structured as follows: Section 2 presents the data collection methodology and taxonomies for content analysis. Section 3 reports the results of the descriptive analysis and the content analysis in each category. The key issues, such as new trade-offs, the evolution of supply chain themes, and the research opportunities, are presented in Sections 4 and 5. Finally, the conclusion is provided in Section 6.

\section{Methodology}

\subsection{Data Collection and Validation}

This study employs a systematic literature collection approach based on a stringbased search and specific validation process; see Figure 1. First, relevant publications, including journal articles and conference articles written in English, were searched on the core collection of Web of Science (WoS) using the following search string in Title, Abstract or Keywords: (cross-border OR multinational OR global OR international OR transnational) AND ("supply chain" OR logistics) AND (tax* OR tariff* OR duty OR customs), and the time span covers all the publication years, i.e., from 1965 to 2020, and more than 400 articles were searched. Furthermore, this study refined the search results by limiting the WoS categories of the publications to Operations Research and Management Science, Management, and Business, and 98 publications remained for further validation. To ensure the relevance of the 98 publications to the focus of this research, i.e., taxes in CBSC modeling, the authors of this article further read the abstracts of these publications and filtered them according to the following validation principles:

- The publication must focus on CBSC management from the enterprises' perspective. This excludes articles with a political or economic focus.

- The effect of tax-related factors must be one of the major considerations in the construction of CBSC decision models.

Ultimately, this process led to the final group of 71 pertinent articles, which are further discussed in the review section.

The other articles, when deemed relevant but not addressing the core topic of this review, are referred to in other sections of this paper. It should be noted that there is a series of research in the accounting and financing field providing rich management insights for MNFs to cope with international taxation, such as Baldenius and Reichelstein [17], Baldenius et al. [18] and Pfeiffer et al. [19]. However, they are not included in the scope of this review because their focus is not on the CBSC management. 


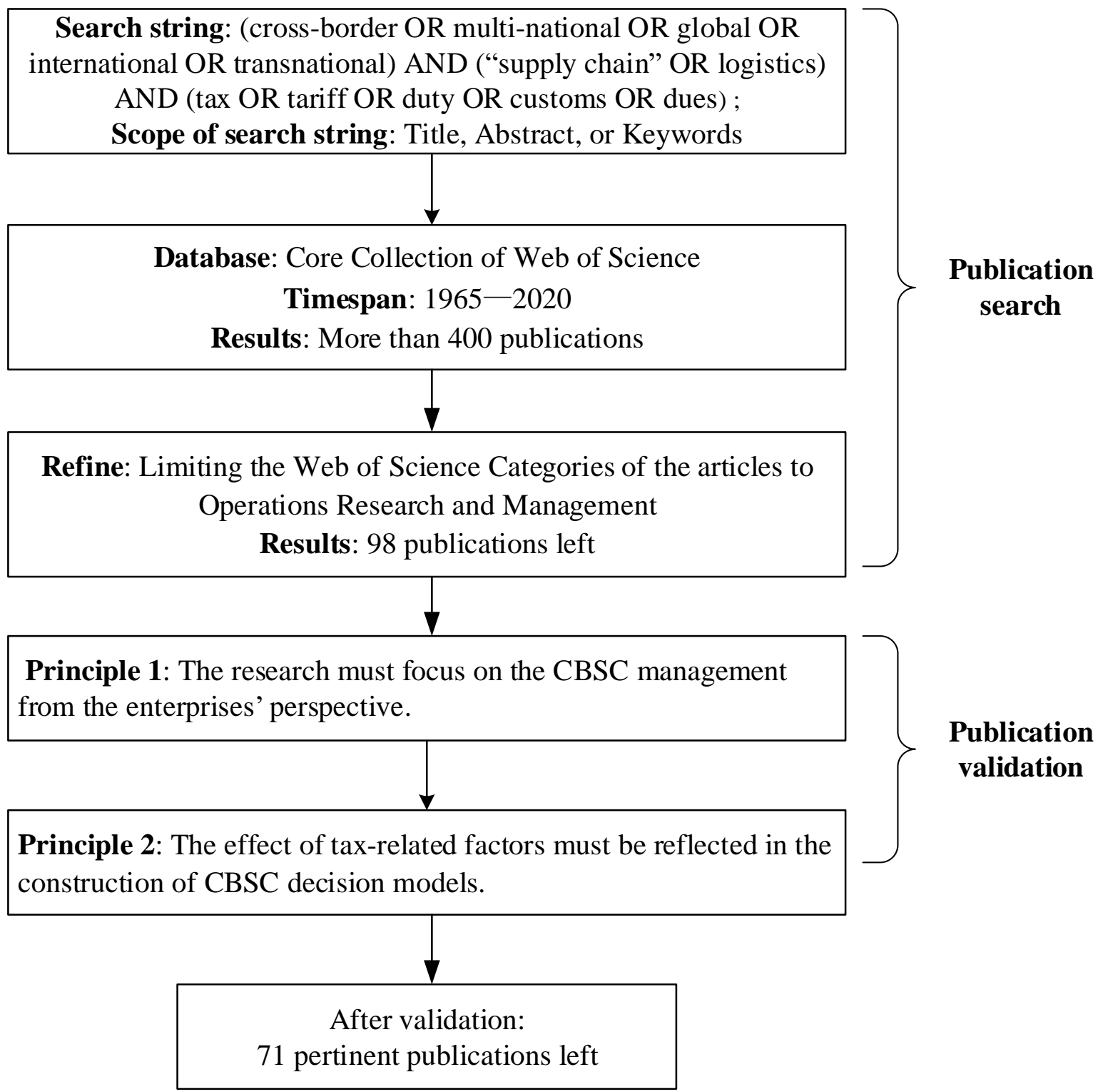

Figure 1. Material selection and validation.

\subsection{Coding Process}

Following the research purpose, four dimensions, namely, supply chain themes, research methodologies, tax types, and illustration types, were defined. According to the coding process model constructed by Mayring [20], these four dimensions were categorized individually (see Table 1). The authors of this article analyzed the entire text of the selected publications and classified them into the corresponding categories in Table 1. In selecting the categories under each dimension, this study adopted the practice of existing review articles (see the right column in Table 1) and pursued inductive analysis of the selected publications. The four-dimensional database constructed by this coding process facilitates the analysis in Section 3. 
Table 1. Structural dimensions and categories for the coding process.

\begin{tabular}{ll}
\hline Dimension and Categories & References \\
\hline Dimension 1: Themes & Van Mieghem [21]; Snyder L V [22] \\
- Supply chain network & Inductively deduced \\
- Manufacture & \\
- Distribution & \\
- Procurement & \\
- Emission & Ghadimi et al. [23]; Meixell et al. [24] \\
\hline Dimension 2: Research methodologies & Inductively deduced \\
- Mathematical modeling & \\
- Empirical modeling & \\
- Simulation modeling & \\
- Conceptual modeling & Henkow and Norrman [6] \\
\hline Dimension 3: Tax types & Inductively deduced \\
- Corporate income tax category & \\
- Tariffs category & \\
- Environmental tax category & \\
- Value-added tax category & \\
\hline Dimension 4: illustration types & Ghadimi et al. [23] \\
- Numerical solution & Inductively deduced \\
- Theoretical solution & \\
\hline
\end{tabular}

The works presented in Wilhelm et al. [25] are utilized as an example to demonstrate the coding process in this article. Wilhelm et al. [25] constructed a mixed integer programming (MIP) model to assist decisions on the design of the CBSC network under the impact of the North American Free Trade Agreement (NAFTA), and a numerical solution was utilized to illustrate the effectiveness of the model. (1) For the theme dimension, this paper focused on the design of the CBSC network, so it clearly falls into the supply chain network category. (2) For the research methodologies dimension, this paper constructed an MIP model, which falls into the mathematical modeling category. (3) For the tax type dimension, this paper focused on the tariff advantages and the rules of origin restrictions imposed by NAFTA, which obviously belong to the tariff category. (4) For the illustration dimension, numerical solution-based commercial software was utilized to illustrate model effectiveness, and it is classified into the category of numerical solution.

\subsection{Validation of Coding Process}

The coding process in Section 2.2 has the limitation of subjectivity. To ensure objectivity, this article adopts the double-check guidelines accepted by Ghadimi et al. [23] and Rebs et al. [26]. The coding process was completed independently by the first author and the second author. Then, in the case of inconsistencies, the third author participated in jointly determining the final coding category. To ensure the reliability of the coding process, this article calculated the Cronbach coefficient $(\alpha)$ proposed by Cronbach [27]. The Cronbach coefficient of the coding process in this article, which is the proportion of total pairwise agreements between different authors, was calculated to be 0.8 , which is higher than the acceptance threshold of 0.7 [27]. Nevertheless, it must be acknowledged that the content analysis method still has a subjective flaw in judging the categories of the selected articles. 


\section{Descriptive and Content Analysis of Taxes in CBSC Modeling}

This section describes the descriptive analysis and content analysis of the selected publications to determine the publication distribution (including time distribution, regional distribution and journal distribution), most influential articles and authors, supply chainrelated themes, tax types, applied research methodologies, and illustration types.

\subsection{Publication Distribution}

Figure 2 depicts the selected publication numbers for each year, describing the research tendency at the interface between taxes and CBSC modeling. The annual publication numbers have increased in recent years, especially from 2011 onwards, and this period contains $76.01 \%$ of the total selected publications. The average number of publications per year from 2018 to 2020 was 8.67, which significantly exceeded the overall average (2.73 publications per year).

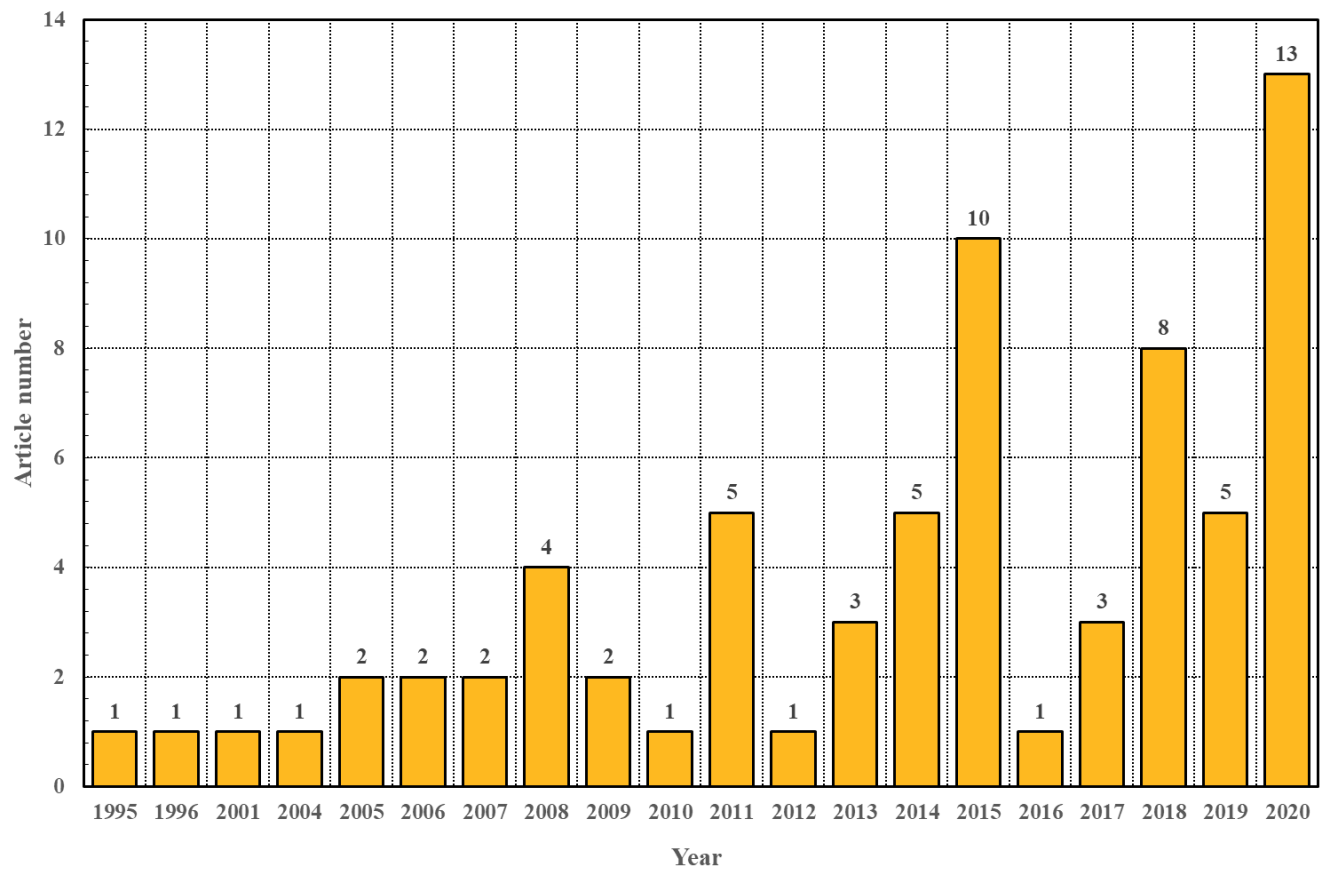

Figure 2. Time distribution of selected publications.

Overall, there is a generally increasing trend in the annual publication numbers from 2005-2020. In addition, there is noticeable growth in 2015 (10 publications), and the publication number reached a new peak in 2020 (13 publications), indicating that the impact of taxes has attracted growing concern from supply chain researchers in recent years. In addition, although this topic has long been proposed, e.g., since 1995 by Arntzen et al. [28], the interface between taxes and CBSC modeling remains at an early stage with a relatively small annual publication number (at most 13).

In addition, the regional distribution and journal distribution of the selected publications, top-cited publications, and most influential authors are presented in Supplementary Materials S1-S4.

\subsection{Supply Chain Themes Addressed}

Figure 3 presents the number of selected articles in each category from the supply chain themes dimension. According to the supply chain-related themes, all the selected publications were divided into six categories, i.e., supply chain network, manufacture, distribution, procurement, emissions, and multi-type focus. These thematic categorizations were extracted from the work of Van Mieghem [21] and Snyder L V [22]. 


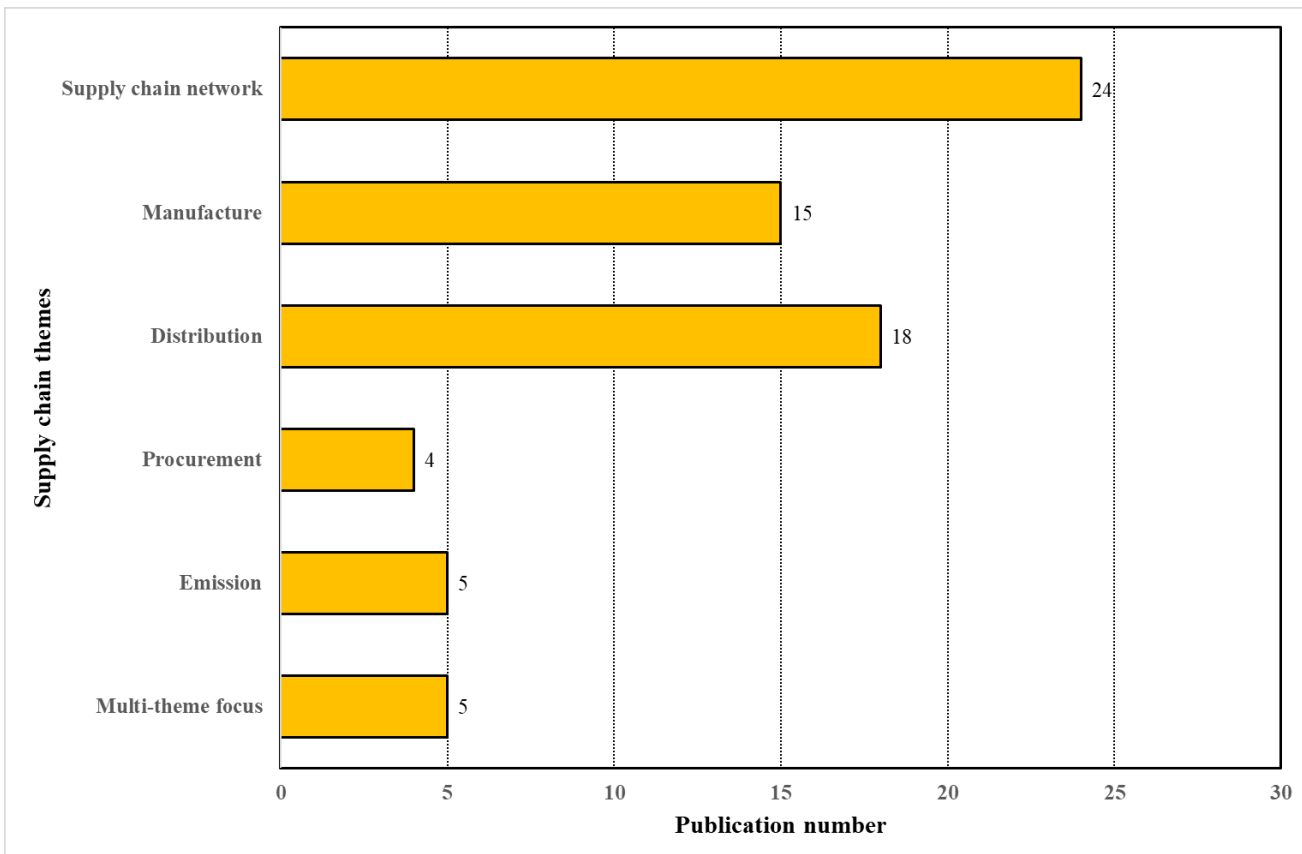

Figure 3. Supply chain themes category of the selected publications.

As shown in Figure 3, the number of selected articles in each category from the supply chain themes dimension was not evenly distributed. Among them, the supply chain network category contains the most literature ( 24 articles, accounting for $34 \%$ ), followed by the distribution category (18 articles, accounting for $25 \%$ ), manufacture category (15 articles, accounting for $21 \%$ ), emission category ( 5 articles, accounting for $7 \%$ ), multi-theme focus category ( 5 articles, accounting for $7 \%$ ), and procurement category ( 4 articles, accounting for $6 \%$ ). In addition, the detailed classification results are presented in Table 2.

Table 2. Publications in each category from the themes dimension.

\begin{tabular}{ll}
\hline Themes Category & Publications \\
\hline Supply chain network (24) & Cohen and Lee [4]; Prataviera et al. [29]; Sabet et al. [30]; Mariel and Minner [31]; Tomoyuki Urata [32]; \\
& de Matta and Miller [33]; Fernandes et al. [34]; Hasani et al. [35]; Mariel and Minner [36]; Yuan Zhou [37]; \\
& Hamad and Gualda [38]; Hammami and Frein [39]; Bassett and Gardner [40]; Fahimnia et al. [41]; Feng and \\
& Wu [8]; Hamad and Gualda [42]; Miller and de Matta [43]; Tsiakis and Papageorgiou [44]; Vila et al. [45]; \\
& Chakravarty [46]; Wilhelm et al. [25]; Fandel and Stammen [47]; Vidal and Goetschalckx [48]; \\
& Arntzen et al. [28]. \\
\hline Manufacture (15) & Handfield et al. [16]; Niu et al. [49]; Prataviera et al. [50]; Turken et al. [51]; Lu and Wu [52]; Oliver \\
& Schenker [13]; Singh et al. [12]; Xiao et al. [53]; Choi et al. [54]; Bogataj and Bogataj [55]; Hameri and \\
& Hintsa [56]; Lu et al. [57]; Kazmer and Roser [58]; Lu and Yang [59]; Huchzermeier and Cohen [60]. \\
\hline Distribution (18) & Dong and Kouvelis [61]; Gao [62]; Wang et al. [63]; Nagurney et al. [64]; Niu et al. [65]; Niu et al. [66]; \\
& Kim et al. [67]; Wu and Lu [68]; Zhang et al. [69]; Shunko et al. [70]; Gao and Zhao [62]; Huh and Park [71]; \\
& Henkow and Norrman [6]; Kumar and Sosnoski [72]; Matsui [73]; Hsu and Zhu [9]; Perron et al. [74]; Shunko \\
& and Gavirneni [75]. \\
\hline Procurement (4) & Hsu and Hu [14]; Cui and Lu [76]; Niu et al. [77]; Xu et al. [10]. \\
\hline Emission (5) & Fang et al. [78]; Micheli and Mantella [79]; Bonilla et al. [80]; Fahimnia et al. [81]; Hammami et al. [82]. \\
\hline Multi-theme focus (5) & \\
\hline Network design \& Emission & Soysal et al. [83]. \\
\hline Manufacture \& Distribution & Masha Shunko [84]; Wang et al. [85]. \\
\hline Manufacture \& Procurement & Zhen [86]. \\
\hline Emission \& Distribution & Allevi et al. [87]. \\
\hline
\end{tabular}




\subsubsection{Supply Chain Network Category}

Articles in the supply chain network category are mainly focused on the topology of network, consisting of various nodes in the supply chain, such as suppliers, manufacturers, logistics hubs, and retailers, including the location and capacity setting of the different nodes, the design of network edges, and the material flow allocation among the network [88]. The tax-related costs, accompanied by the cross-border shipping flows, will change the freight flow toward different tariff sovereign areas and then affect plants and hubs' configuration. When MNFs make CBSC network decisions, the main tax-related issues considered include the rules of origin restrictions [25,31], tariffs and CIT rates in different regions [8,30], and FTA impacts [25,31]. In addition, carbon tariffs and environmental taxes in some regions, such as the European Union (EU), force MNFs to consider carbon emissions when designing CBSC networks $[42,83]$. In addition, to cope with changes in tax policies, especially tariff regulations, MNFs often need to adjust the existing CBSC network. In this case, the costs from facility closure and capacity transfer will be the main factors affecting CBSC redesign [39].

From the perspective of modeling objective function, articles in this category can be divided into two sorts: research with the goal of minimizing cost and maximizing after-tax profit. Although there is no difference in mathematical analysis between these two types of models, the focus of the research is different. For the former, researchers usually focus on the trade-offs between fixed costs (such as plant construction, equipment purchase) and variable costs (such as unit transportation costs, labor costs) [44], and the models are usually based on deterministic assumptions [42,44]. This kind of research pays more attention to the long-term design of the CBSC (more than 3 years) [28]. For the latter, because the impact of demand is directly reflected in the objective function of the model, which brings more expansion directions to the CBSC network design model, specifically, the randomness of demand and capacity is incorporated into the CBSC network design model, which brings rich enlightenment to MNFs [30]. For example, when considering the demand and capacity fluctuations, setting up spare capacity and increasing distribution channels are better choices for MNFs to design CBSC network [35].

\subsubsection{Manufacturing Category}

The focus of the articles in the manufacturing category is mainly related to the process from raw materials to finished products, such as manufacturing capacity and technology investment, manufacturing postponement and offshoring strategy, and the quantity and quality of products.

Some of the research in this category focuses on the manufacturing capacity-level management. The impacts of CIT incentives in different regions are the most obvious for the capacity investment decisions in a CBSC. On the one hand, for MNFs investing in countries with high labor costs and cross-border transport risks, such as natural disasters and port strikes, CIT incentives are important compensation [57,59]. On the other hand, the tax-crediting policy, which is aimed at avoiding double taxation on CIT in different countries, can significantly reduce the optimal capacity of MNF whose target is maximize after-tax profitability [53]. In addition to CIT, the emission-tax regulations in some regions, such as EU, can largely affect the green technology investment decisions and force MNFs to offshore outsourcing manufacturing capacity with high emissions [51].

There are also several articles focus on manufacturing postponement strategy under the impact of tariffs. The manufacturing postponement refers to determining which operations should be executed in which country. In a CBSC, because of the impact of international taxes, both the manufacturing country and the storage form (semi-finished or finished goods) will affect the supply chain tariff costs significantly [50]. For example, for some commodities, especially in industrial products, the value of finished products is far from raw materials, which provides MNFs with opportunities to reduce the overall tariff cost among CBSC by arranging the assembly links of the final product in the market 
country [8]. Moreover, to a certain extent, the FTAs and bonded regulations in some regions magnifies the impact of tariff costs on MNF's manufacturing postponement decision [54].

In addition, research on the trade-offs among tax benefits, labor costs, and cross-border risks has provided MNFs with meaningful insights to cope with the challenges brought by the offshore outsourcing strategy $[55,85]$.

\subsubsection{Distribution Category}

The distribution category in this paper focuses on the transactions between upstream and downstream members (including final customers) in a CBSC, such as the logistics mode, product allocation, and channel structure of distribution.

Most of the research in this category focuses on the setting of transaction prices between supply chain members. In practice, the headquarters of MNFs often set the transaction prices of products between plants and distribution centers located in different countries to exploit the CIT rates of different countries [67,70]. The above CIT savings strategy is known as the transfer pricing strategy. However, the countries upstream in the CBSC will enforce specific tax rules, such as the arm's length principle, to restrict MNFs' transfer pricing strategy $[68,73]$. The abovementioned restrictions will encourage structural changes in the traditional CBSC distribution decision-making model, and a detailed treatment of this topic can be found in Huh and Park [71] and Shunko and Gavirneni [75].

Some of the research focuses on the product-to-market material flow affected by the tariffs. In fact, the preferential tax policies offer MNFs with tax-saving opportunities by adjusting the equilibrium material flow towards different regions [64]. Moreover, the timeliness and the logistics mode of cross-border delivery will also be affected by the tariff rate of the importing country, and the detailed treatment can be found in the research of Wang et al. [63]. Furthermore, in recent years, MNFs' distribution strategies in different regions face the challenges from the intensification of trade barrier debates and growing uncertainties in trade policies between countries [61].

Last, the VAT collection regulation is another important factor influencing an MNF's distribution strategy, especially the establishment distribution channel. Taking China's export-oriented tax regulations as an example, MNFs can use the strategy of "exporting to domestic sales" to enjoy a VAT refund, which is costly from a logistics perspective but substantially reduces the tax burden of the supply chain [9].

\subsubsection{Procurement Category}

Articles in the procurement category focus on topics related to the acquisition of raw material, such as procurement mode and purchasing quantity.

There are two kinds of research concerns in this category. The first is about the relationship of procurement mode and the export-oriented tax rules in developing country. In reality, there are two procurement modes widely adopted by MNFs, namely consignment strategy and turnkey strategy. From the observation on the greater China region, the exportoriented tax rules in China indirectly affect MNF's preference for the two procurement modes [10].

The latter is about the impact of tariffs on the supplier selection and procurement quantity of MNFs. In practice, the tariffs cost levied on the imported raw materials often encourages MNFs to purchase locally, and the appropriate tariff rate can improve product quality and social welfare in the domestic market [77]. In addition, to increase the proportion of domestic raw materials in the final product, the host countries often set rules of origin to encourage MNFs to increase local procurement [76].

\subsubsection{Emissions Category}

The emissions category concerns the environmental externalities of CBSC operations. In recent years, widespread concern about global climate change has prompted some countries to enforce a series of tax policies to reduce carbon emissions $[89,90]$, such as 
carbon tariffs [91] and environmental policies [92]. In this context, some articles have focused on the CBSC's carbon emissions and analyzed the impact of environmental taxation policies on the CBSC operations.

Carbon tariffs internalize MNFs' emission costs, thereby affecting MNFs' supply chain decisions. For example, a survey on the EU economy shows that the carbon emissions from production and transportation caused by offshore manufacturing are the main reasons for the increase in the carbon footprint of some industries. Carbon tariffs encourage MNF managers to transfer production to the EU to reduce products' carbon footprint [80]. Moreover, due to the impact of the carbon tax, the trade-offs between operational costs and carbon emissions can help MNFs achieve rational investment decisions, and the marginal cost of supply chain operations increased by the carbon tax can achieve the most significant environmental benefits [81].

In addition to the direct carbon tax, there are three other environmental policies for corporations' carbon emissions, i.e., carbon cap, cap-and-trade, and cap-and-offset [79].

\subsubsection{Multi-Theme Category}

The remaining articles were coded in the category of multi-theme focus. Due to growing environmental concerns, minimizing carbon emissions has become another vital modeling objective, along with minimizing total logistics cost, in the design of CBSC networks [84]. Moreover, the environmental policies could considerably affect the distribution channels and production choices of MNFs, for example, the application of the European Union Emissions Trading System (EU-ETS) have largely decreased the distance between a couple of closed-loop supply chain tiers [87].

Furthermore, in many cases, tax collection regulations such as the arm's length principle and rules of origin will affect the MNF's production outsourcing decision, as well as distribution channels $[84,85]$ and global procurement strategies [86].

\subsection{Research Methodology Dimension}

Figure 4 presents the number of publications in each category from the supply chain themes dimension. According to the methodologies applied in the research, all selected articles were divided into four categories, i.e., mathematical modeling, simulation modeling, empirical modeling, and conceptual modeling.

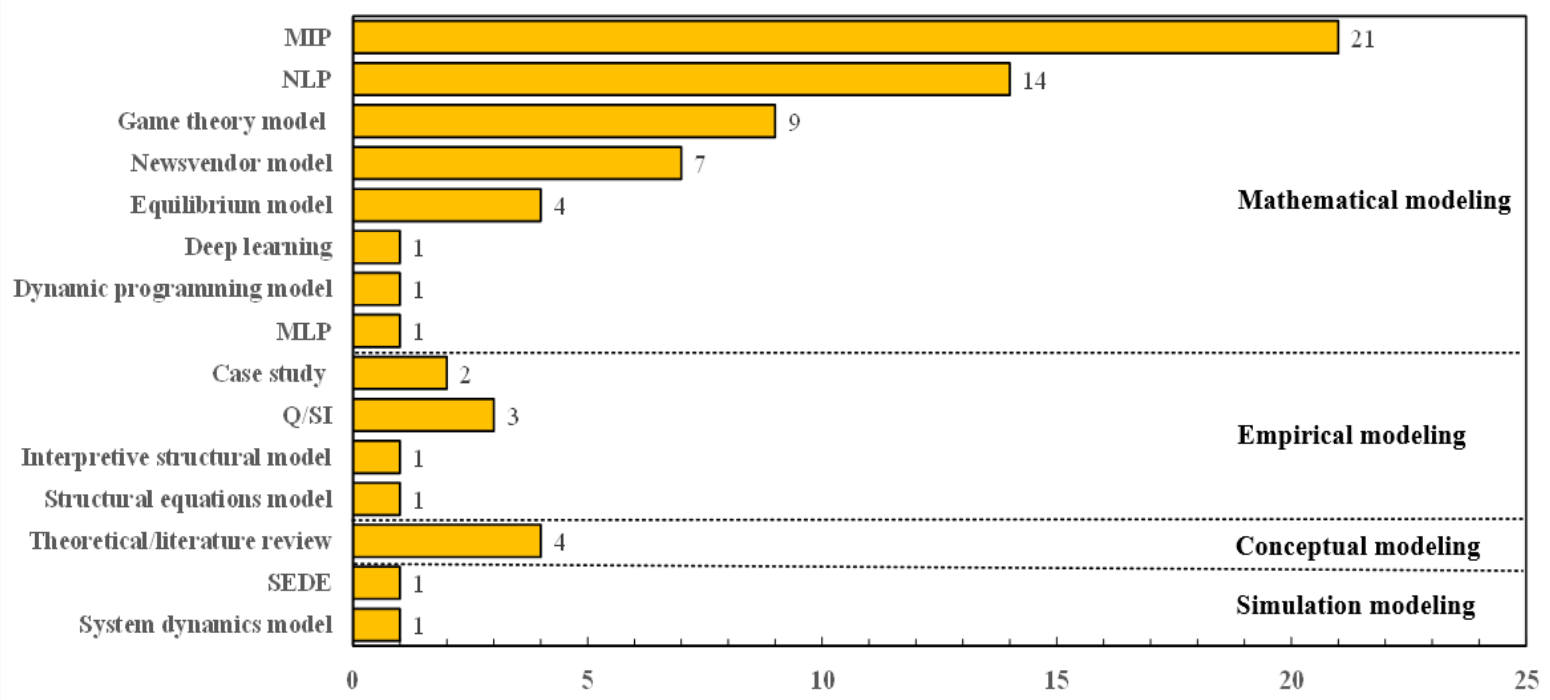

Figure 4. Research methodology category of the selected publications. Note: MIP $=$ Mixed integer programming model, NLP = Nonlinear programming model, MLP = Multi-objective linear programming model, Q/SI = Questionnaire survey/Semi-structured interviews, and SEDE = Simulation experiment based on discrete events. 
More specifically, fifty-eight articles (accounting for 82\%) in the mathematical modeling category are further divided into eight subcategories, including MIP (21 articles), NLP (14 articles), game theory model ( 9 articles), newsvendor model ( 7 articles), equilibrium model (4 articles), deep learning ( 1 article), dynamic programming model ( 1 article), and MLP (1 article). Moreover, seven selected articles (accounting for 10\%) coded into the empirical modeling category are further divided into four subcategories, including Q/SI ( 3 articles), case study ( 2 articles), interpretive structural model ( 1 article), and structural equations model ( 1 article). In addition, four review articles (accounting for $6 \%$ ) were coded into the conceptual modeling category. Furthermore, the remaining two selected articles (accounting for $3 \%$ ) were coded into the simulation modeling category. The detailed classification results are exhibited in Table 3.

Table 3. Category of methodologies applied in selected articles.

\begin{tabular}{lll}
\hline Method Category & Methodology Approach & Publications \\
\hline Mathematical modeling (58) & $\begin{array}{l}\text { Mixed integer programming } \\
\text { model (MIP) (21) }\end{array}$ & $\begin{array}{l}\text { Sabet et al. [30]; Micheli and Mantella [79]; Tomoyuki } \\
\text { Urata [32]; de Matta and Miller [33]; Hammami et al. [82]; }\end{array}$ \\
& & Hasani et al. [35]; Mariel and Minner [36]; Yuan Zhou [37]; \\
& Hamad and Gualda [38]; Bassett and Gardner [40]; \\
& Fahimnia et al. [41]; Perron et al. [74]; Feng and Wu [8]; \\
& $\begin{array}{l}\text { Hamad and Gualda [42]; Miller and de Matta [43]; Tsiakis } \\
\text { and Papageorgiou [44]; Vila et al. [45]; Wilhelm et al. [25]; } \\
\end{array}$ \\
& Fandel and Stammen [47]; Vidal and Goetschalckx [48]; \\
& Arntzen et al. [28].
\end{tabular}

Non-linear programming model Dong and Kouvelis [61]; Turken et al. [51]; Kim et al. [67];

(NLP) (14) Singh et al. [12]; Zhang et al. [69]; Mariel and Minner [31];

Shunko et al. [70]; Wang et al. [85]; Fahimnia et al. [81]; Gao and Zhao [62]; Hammami and Frein [39]; Masha Shunko [84]; Zhen [86]; Chakravarty [46].

Game theory model (9) $\quad$ Fang et al. [78]; Niu et al. [49]; Cui and Lu [76]; Niu et al. [77]; Niu et al. [65]; Niu et al. [66]; Wu and Lu [68]; Xu et al. [10]; Matsui [73].

\begin{tabular}{lll}
\hline & Newsvendor model (7) & $\begin{array}{l}\text { Hsu and Hu [14]; Lu and Wu [52]; Wang et al. [63]; } \\
\text { Xiao et al. [53]; Huh and Park [71] Hsu and Zhu [9]; Shunko } \\
\text { and Gavirneni [75]. }\end{array}$ \\
\hline & $\begin{array}{l}\text { Equilibrium model (4) } \\
\text { Bogurney et al. [64]; Allevi et al. [87]; Oliver Schenker [13]; }\end{array}$ & $\begin{array}{l}\text { Soysal et al. [83]. } \\
\text { pulti-objective linear } \\
\text { programming model (MLP) (1) }\end{array}$ \\
\hline Dynamic programming model (1) & Huchzermeier and Cohen [60]. \\
\hline Empirical modeling (7) & Deep learning (1) & Guo [62]. \\
\hline & Structural equations model (1) & Bonilla et al. [80]. \\
\hline & Interpretive structural model (1) & Kumar and Sosnoski [72]. \\
\hline & $\begin{array}{l}\text { Questionnaire } \\
\text { surveys/Semi-structured } \\
\text { interviews (3) }\end{array}$ & Henkow and Norrman [6]; Lu et al. [57]; Lu and Yang [59]. \\
\hline Case study (2) & Prataviera et al. [29]; Kazmer and Roser [58]. \\
\hline Simulation modeling (2) & Theoretical/literature review (4) & $\begin{array}{l}\text { Cohen and Lee [4]; Handfield et al. [16]; } \\
\text { Prataviera et al. [50]; Hameri and Hintsa [56]. }\end{array}$ \\
\hline & $\begin{array}{l}\text { Simulation experiment based on } \\
\text { discrete events (1) }\end{array}$ & Fernandes et al. [34]. \\
\hline
\end{tabular}




\subsubsection{Mathematical Modeling Category}

Most of the selected articles were coded into mathematical modeling category (58 publications, accounting for $82 \%$ ), and there are 8 types of methodological approaches in this category. Specifically, the MIP is the major methodology applied to assist in CBSC decisions. The early research of Arntzen et al. [28] was considered foundational (with 432 in global citation score) to the application of the mixed-integer programming model to the CBSC network design problem. The objective of this kind of model is usually to maximize the global after-tax profits computed in the numeraire country's currency. Profits here are generated by sales revenue derived from the material flows from the plants to other plants (transshipments) and to destination countries (DCs) as well as from DCs to markets minus all fixed and variable costs (i.e., production, transportation, and facility fixed costs). The tax costs are calculated by multiplying an MNF's income by a certain tax rate. Based on the paradigm of the mathematical programming model, CBSC network design models have evolved in two directions. First, the decision variables became more diverse, i.e., more types of decision variables are embedded in the construction of the CBSC network design model, such as transfer pricing $[33,43,48]$ and marketing decisions [30]. Second, they consider the impact of new global factors in the construction of decision models, such as product recycling [35,47], FTA impacts [25], emission controls [42], and tax regulation impacts [8].

In addition, there are 14 publications applied NLP models. Some NLP models, such as that in Mariel and Minner [31], represent extensions of the MIP model by adding nonlinear functions in the constraints or objectives, and their structure is similar to MIP models but more dependent on efficient solving algorithms. Other contributions, such as Dong and Kouvelis [61] and Shunko et al. [70], sought to develop structured optimization models to improve the current understanding of the impact of taxes. Moreover, game theory models and newsvendor models have unique advantages in exploring the interactivity of decision-making among different supply chain members and obtaining universal managerial insights $[14,49,78]$. The models in this kind of research are usually based on strong assumptions, and strive to provide closed-form solutions to provide decision support for MNFs. However, the relevant research can be divided into two brands based on the assumption of the demand function. The former is based on deterministic assumptions. By assuming that the relationship between demand and pricing is a linear negative correlation function with known parameters, a convex income function is constructed, and then the equilibrium decisions of supply chain members is obtained based on optimality conditions. The detailed treatment can be found in the research of Niu et al. [66] and $\mathrm{Xu}$ et al. [10], and their model results show that the parameters that could significantly affect the decision-making of MNFs include market capacity, demand price sensitivity coefficient and tax rate. The latter is based on the stochastic assumptions. By assuming the probability distribution of the demand error, the optimal capacity and pricing decisions are further explored, the detailed treatment can be found in the research of Fang et al. [78] and Shunko et al. [70], and they found that main factors that affect the decision-making of MNFs are the demand variance and the risk preference coefficient of decision-makers.

Besides, the equilibrium model is another effective tool to analyze material flow in a CBSC, and tax-related costs and policies are treated as obstacles to [13] or quotas for [64] the material flow in this kind of approach. The remaining three publications in this category applied a multi-objective linear programming model [83], dynamic programming model [60] and deep learning model [93] in their works on the flexible operations of CBSCs.

\subsubsection{Empirical Modeling Category}

There are four specific approaches in this category, i.e., structural equations model, interpretive structural model, questionnaire surveys/semi-structured interviews and case studies. Among them, questionnaire surveys and semi-structured interviews are mostly adopted to obtain empirical data on issues such as the opinion gaps between financial personnel and logistics personnel for supply chain concepts [6] and the investment preferences of multinational manufacturers $[57,59]$. 
In addition, the case study method and the interpretive structural model are straightforward methods to illustrate the effect of taxes in specific situations [50,58,72]. Moreover, the structural equations model is an effective quantitative method to measure the carbon footprints of products at the sectoral level [80].

\subsubsection{Conceptual Modeling Category}

The articles in the conceptual modeling category are intended to provide theoretical guidelines for MNFs in tax planning and CBSC optimizations. In the current global business environment where the impact of trade frictions and rules of origin restrictions are common, it is necessary to identify the effect of new risk factors, such as tariff barriers and changes in RTAs [4]. In addition, it is qualitatively demonstrated that both the manufacturing country and the storage form (semi-finished or finished goods) significantly affect the supply chain tax costs in a CBSC, so the definition of the scope of the manufacturing postponement strategy is important for MNFs [50].

\subsubsection{Simulation Modeling Category}

Two simulation approaches, i.e., a system dynamics model and simulation experiment based on discrete events, were utilized to simulate different global production strategies in a CBSC. Specifically, as a representative tool for simulating continuous systems [94], a system dynamics model can effectively simulate the multistage production process in a CBSC and analyze the impact of changes in factors such as tax rates and transportation costs [54]. Simulation experiments based on discrete events have unique strengths in the numerical solution and analysis of complex real-world CBSC systems [34].

\subsection{Tax Type Dimension}

Figure 5 presents the number of publications in each category from the tax type dimension. According to the tax types considered in this research, the selected articles were divided into five categories, i.e., the CIT category, environmental tax category, tariff category, VAT category, and multi-type taxes category.

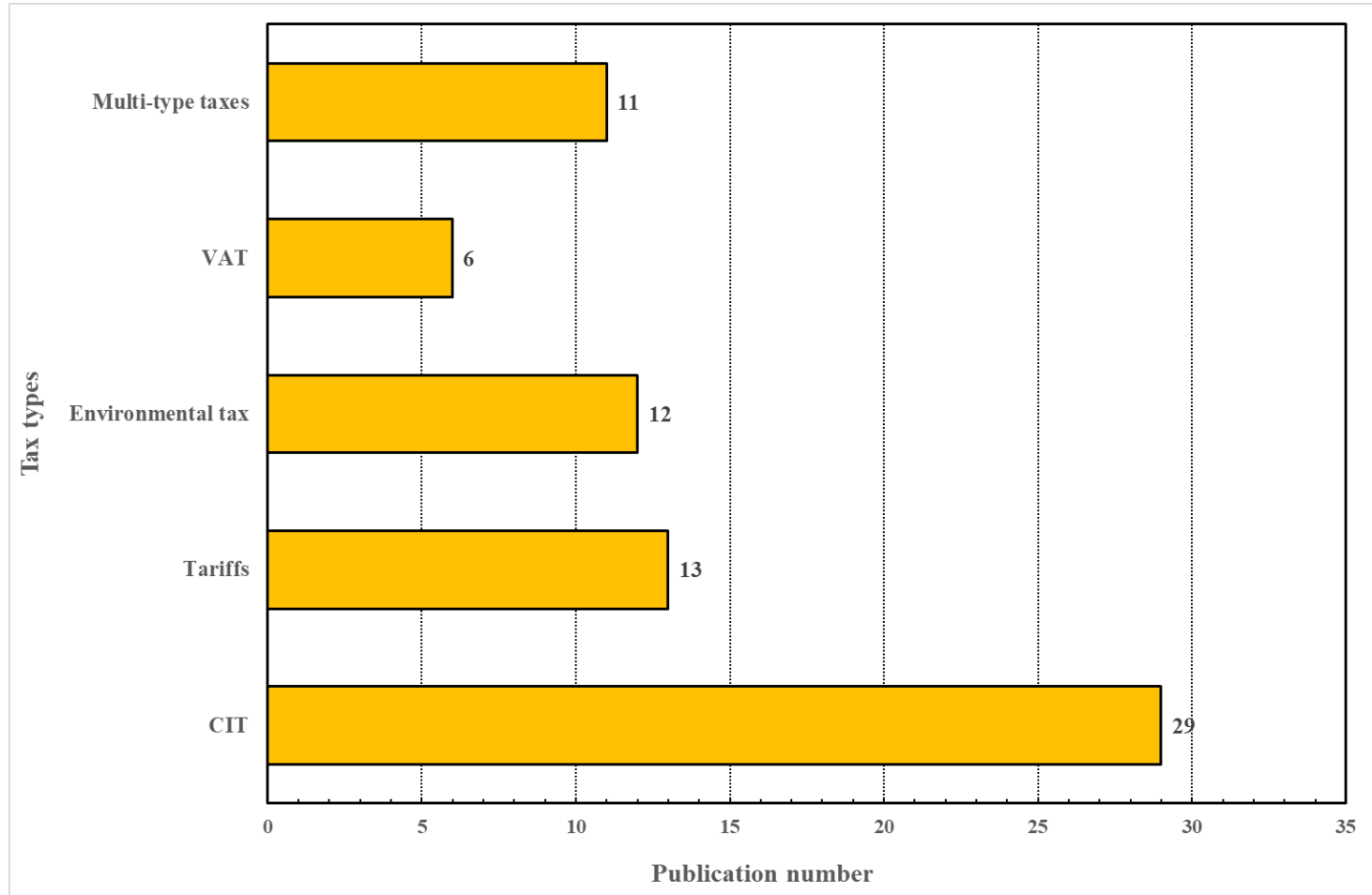

Figure 5. Tax type category of the selected publications. 
Among different categories from the tax type dimension, the CIT category contains the most literature ( 29 articles, accounting for $41 \%$ ), followed by the tariffs category (13 articles, accounting for $18 \%$ ), environmental tax category (12 articles, accounting for $17 \%$ ), multi-type taxes category ( 11 articles, accounting for $15 \%$ ), and VAT category ( 6 articles, accounting for $8 \%$ ). The detailed classification results were exhibited in Table 4 .

Table 4. Publications in each category from the type types dimension.

\begin{tabular}{ll}
\hline Tax Types Category & Publications \\
\hline Corporate income tax (29) & Hsu and Hu [14]; Lu and Wu [52]; Prataviera et al. [29]; Cui and Lu [76]; \\
& Niu et al. [65]; Niu et al. [66]; Kim et al. [67]; Wu and Lu [68]; Zhang et al. [69]; \\
& Shunko et al. [70]; Wang et al. [85]; de Matta and Miller [33]; Fernandes et al. [34]; \\
& Gao and Zhao [62]; Xiao et al. [53]; Hamad and Gualda [38]; Hammami and \\
& Frein [39]; Masha Shunko [84]; Huh and Park [71]; Kumar and Sosnoski [72]; \\
& Matsui [73]; Perron et al. [74]; Hameri and Hintsa [56], Lu et al. [57]; Miller and de \\
& Matta [43]; Shunko and Gavirneni [75]; Lu and Yang [59]; Vidal and \\
& Goetschalckx [48]; Huchzermeier and Cohen [60]. \\
\hline
\end{tabular}

Tariffs (13)

Dong and Kouvelis [61]; Handfield et al. [16]; Prataviera et al. [50]; Lu and Wu [52]; Nagurney et al. [64]; Niu et al. [77]; Mariel and Minner [31]; Mariel and Minner [36]; Bassett and Gardner [40]; Fahimnia et al. [41]; Choi et al. [54]; Tsiakis and Papageorgiou [44]; Kazmer and Roser [58].

Environmental tax (12) Fang et al. [78]; Turken et al. [51]; Allevi et al. [87]; Micheli and Mantella [79]; Oliver Schenker [13]; Singh et al. [12]; Tomoyuki Urata [32]; Bonilla et al. [80]; Fahimnia et al. [81]; Hammami et al. [82]; Yuan Zhou [37]; Soysal et al. [83].

\begin{tabular}{ll}
\hline Value-added tax (6) & $\begin{array}{l}\text { Niu et al. [49]; Hamad and Gualda [42]; Xu et al. [10]; Zhen [86]; Bogataj and } \\
\text { Bogataj [55]; Hsu and Zhu [9]. }\end{array}$ \\
\hline Multi-type taxes (11) & \\
\hline - $\quad$ Corporate income tax \& Tariffs & $\begin{array}{l}\text { Hasani et al. [35]; Vila et al. [45]; Chakravarty [46]; Wilhelm et al. [25]; Fandel and } \\
\text { Stammen [47]; Arntzen et al. [28]. }\end{array}$ \\
\hline $\begin{array}{l}\text { Corporate income tax \& Tariffs \& } \\
\text { Value-added tax }\end{array}$ & $\begin{array}{l}\text { Guo [62]; Cohen and Lee [4]; Sabet et al. [30]; Henkow and Norrman [6]; Feng and } \\
\text { Wu [8]. }\end{array}$
\end{tabular}

\subsubsection{Corporate Income Tax Category}

CIT is levied on an MNF's income, which directly affects its benefits and cannot be passed on to downstream consumers. On the one hand, CIT rate gaps offer MNFs opportunities to save tax costs through a transfer pricing strategy. However, cross-border distribution and production strategies also lead to a series of problems, such as the diversification of production costs, the double marginal effect of decentralized decision-making mechanisms $[65,67,85]$, incentives for the retail sector's localized procurement [66], and regional CIT relief policies, which complicate MNFs' CIT-saving operations. Furthermore, the benefits, costs, and risks that need to be weighed in the above decisions are including the loss caused by decentralized decision-making $[65,67,85]$, the costs of affiliated institutions construction and operations [66], risk and power transfer due to the registration of affiliated institutions [70].

On the other hand, in many cases, MNFs need to adjust CBSC operational strategies to account for the impact of specific regulations on their CIT. For example, many countries have adopted the tax cross-credit principle for MNFs' overseas taxes to avoid double taxation of MNF income, which stipulates that MNFs can use the excess tax of overseas subsidiaries (located in high-tax countries) to offset the tax payable in other regions. In this context, MNFs can adjust distribution and offshore outsourcing strategies to increase their total after-tax revenue $[14,53]$. Moreover, some researchers from the logistics operation perspective to analyze how to use the CIT rate differences and CIT relief policies in different countries to help MNFs maximize its' after-tax profits [38,52,57,59]. 


\subsubsection{Tariffs Category}

Tariffs are levied on the goods entering and leaving a country's customs border and are considered an indirect tax because they are passed on to the downstream consumer in most cases. Since 2018, with the rise of trade protectionism, the impact of tariffs on CBSC operations has attracted academic and industry concern.

First, tariffs costs are among the major fiscal constraints that affect the landed cost of products in CBSCs [40,44], and the tariff-refund policies in some countries provide taxsaving opportunities for MNFs by designing an appropriate CBSC network [36]. Second, an increase in tariff rates presents obstacles to MNFs' global procurement strategies and force them to adopt localized procurement strategies [54,77]. The subsequent trade-offs among product quality, procurement costs, and tariff costs complicate MNFs' procurement strategies: on the one hand, to enjoy preferential tariff policies, MNFs prioritize satisfying the rules of origin of consumer countries in the production process [31]; on the other hand, the location of transshipment points, tariffs, and differences in production costs between countries comprehensively determine the effectiveness of the production postponement strategy in CBSCs [54].

In recent years, based on the macro background of the Sino-US trade war, the impact of tariff uncertainty on CBSC network configuration has attracted academic attention [61], and the changes in tariff rates and quota policies will affect the distribution to different markets across the CBSC under equilibrium conditions [64].

\subsubsection{Environmental Tax Category}

The environmental tax category includes a series of taxes that levied on an MNF's operating externalities, and there are three tax bases for environmental taxes: the output of polluting enterprises, the pollutants contained in the inputs of the polluting enterprises, and the enterprise's pollutant emissions.

In practice, offshore manufacturing strategies could significantly increase a CBSC's carbon footprint, and carbon tariffs and R\&D subsidies for the industrial and freight sectors can effectively reduce the CBSC's carbon footprint taxation methods for MNFs' carbon emissions [80]. However, in scenarios where the carbon tariff policies of the countries upstream and downstream in a CBSC are inconsistent, the carbon tariffs often fail to reduce carbon emissions [78].

In addition, the different implementation methods of environmental taxes entail new requirements for CBSC modeling. Taking carbon emissions as an example, there are four application methods for the taxation of MNFs' carbon emissions, i.e., carbon caps, carbon taxes, cap-and-trade, and cap-and-offset. Under the influence of the aforementioned carbon policy, the current CBSC decision-making models, such as production and inventory planning [82] and technology investment decisions [51], face structural changes.

\subsubsection{Value-Added Tax Category}

VAT is a kind of indirect tax based on the added value generated during goods circulation. Although the final consumer usually bears it, VAT collection and rebate regulations for imported and exported goods in specific countries substantially impact a CBSC's operations. Taking China's export VAT rebate regulations as an example, MNFs can enjoy VAT refunds from the government by combining distribution and inventory strategies with the bonded policies of different regions in China [9,42].

Besides, changes in the VAT export refund ratio also affect the preference of MNFs regarding the global procurement strategy and local procurement strategy. When the refund ratio increases, MNFs tend to purchase more locally from the host country to reduce tax costs $[10,86]$.

\subsubsection{Multi-Type Taxes Category}

In some cases, the CIT planning strategy of MNFs will also be affected by tariff costs, and the additional trade-offs are the decreased CIT costs of the local tax incentives and the 
increased tariff costs caused by the cross-border distribution. In the corresponding decision models, tariff costs are characterized as the product of the tariff rate in a specific country on a specific product and the value of the corresponding inbound and outbound goods, while the CIT is the product of the company's total income and the CIT rate in a specific country. A detailed treatment of this topic can be found in Arntzen et al. [28], Wilhelm et al. [25], Vila et al. [45] and Fandel and Stammen [47].

In addition, as Cohen and Lee [4] noted, how to construct decision-making models to help MNFs respond to changes in government tax policies, such as tariff rates and taxation rules on CITs and VATs, is an important research direction in the future of CBSC operations management. Several selected articles comprehensively analyzed the total impact of CIT, tariffs, and VAT on CBSC operations [6,8].

\subsection{Illustration Type Dimension}

This section provides insights regarding the extent of the themes and methodologies presented in Sections 3.4 and 3.5. As shown in Figure 6, three categories, i.e., closed-form solution, numerical solution and theoretical solution, were identified.

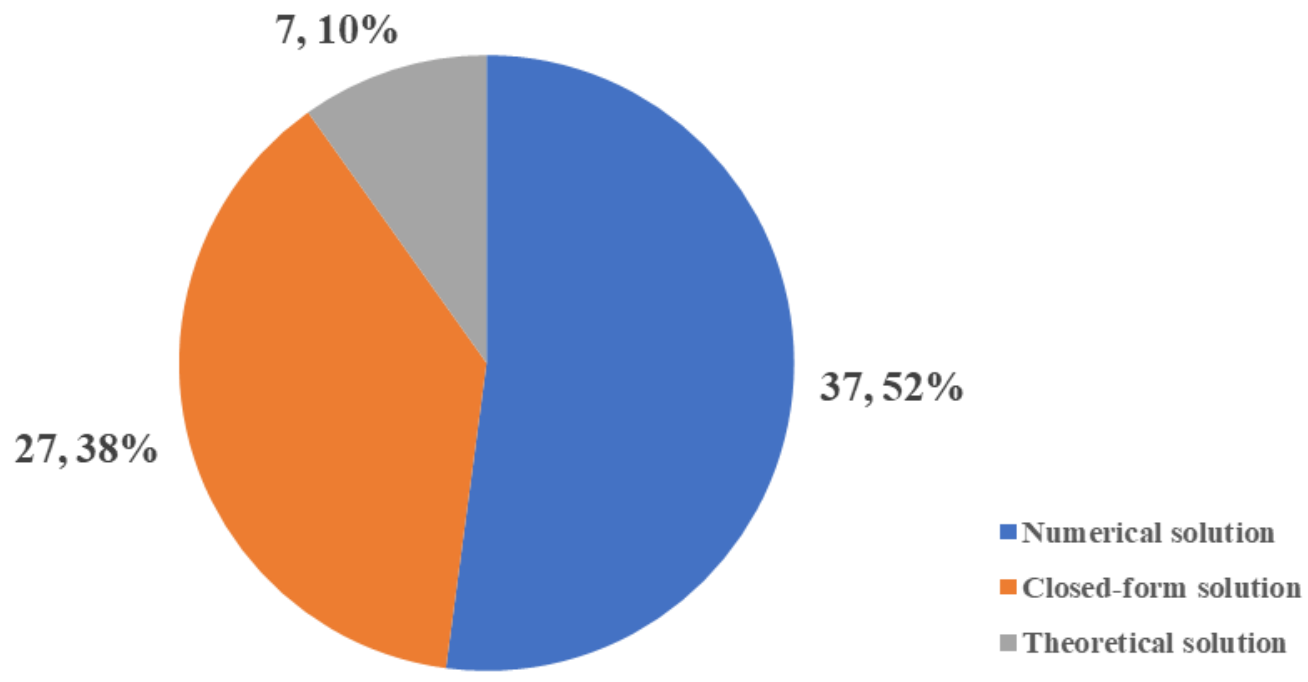

Figure 6. Illustration type category of the selected publications.

From the perspective of illustration type dimension, most of the selected articles (37, accounting for $52 \%$ ) used numerical solutions to illustrate the managerial insights of their research. Additionally, twenty-seven selected articles (accounting for 38\%) use closed-form solutions to illustrate their findings. The remaining seven selected articles (accounting for $10 \%$ ) offered theoretical summaries. The detailed classification results are presented in Table 5 
Table 5. Publications in each category from the illustration types dimension.

\begin{tabular}{ll}
\hline Illustration Types Category & Publications \\
\hline Numerical solution (37) & Guo [62]; Sabet et al. [30]; Nagurney et al. [64]; Allevi et al. [87]; Micheli and Mantella [79]; \\
& Oliver Schenker [13]; Singh et al. [12]; Zhang et al. [69]; Mariel and Minner [31]; Tomoyuki \\
& Urata [32]; Bonilla et al. [80]; de Matta and Miller [33]; Fahimnia et al. [81]; \\
& Hammami et al. [82]; Hasani et al. [35]; Mariel and Minner [36]; Yuan Zhou [37]; Hamad \\
& and Gualda [38]; Hammami and Frein [39]; Soysal et al. [83]; Bassett and Gardner [40]; \\
& Fahimnia et al. [41]; Choi et al. [54]; Bogataj and Bogataj [55]; Perron et al. [74]; Feng and \\
& Wu [8]; Lu et al. [57]; Hamad and Gualda [42]; Miller and de Matta [43]; Tsiakis and \\
& Papageorgiou [44]; Kazmer and Roser [58]; Lu and Yang [59]; Vila et al. [45]; \\
& Wilhelm et al. [25]; Fandel and Stammen [47]; Vidal and Goetschalckx [48]; \\
& Arntzen et al. [28]. \\
& Dong and Kouvelis [61]; Fang et al. [78]; Niu et al. [49]; Turken et al. [51]; Hsu and Hu [14]; \\
& Wang et al. [63]; Lu and Wu [52]; Cui and Lu [76]; Niu et al. [65]; Niu et al. [77]; \\
& Niu et al. [66]; Kim et al. [67]; Wu and Lu [68]; Xu et al. [10]; Shunko et al. [70]; \\
& Wang et al. [85]; Fernandes et al. [34]; Gao and Zhao [62]; Xiao et al. [53]; Masha \\
& Shunko [84]; Zhen [86]; Huh and Park [71]; Matsui [73]; Hsu and Zhu [9]; Shunko and \\
& Gavirneni [75]; Chakravarty [46]; Huchzermeier and Cohen [60]. \\
\hline Closed-form solution (27) & Handfield et al. [16]; Cohen and Lee [4]; Prataviera et al. [29]; Prataviera et al. [50]; Henkow \\
& and Norrman [6]; Kumar and Sosnoski [72]; Hameri and Hintsa [56].
\end{tabular}

\subsubsection{Numerical Solution Category}

Among the selected articles in numerical solution category, twenty-one were based on real-world business cases. The practical cases used in the illustration varied, including automotive production [36] and the production and distribution of chemical products [40]. Note that most researchers constructing mixed-integer models for analysis prefer to adopt a real case to illustrate the model's practicality. Another 16 selected articles used standardized numerical examples to demonstrate their models' competence. Different from the research based on real-world business cases, it is valuable and easy to implement standardized numerical examples to test and complete newly constructed models.

For papers utilizing numerical solutions, the construction of a solution algorithm is an essential part of the research. Among them, Benders decomposition and branching and bounding are two effective methods to solve the exact solution of the CBSC network design problem [31,48]. In addition, commercial optimization software, such as Lingo and Complex, is also widely used to obtain numerical solutions for most MIP models [45,79]. In addition, for the NLP models in the articles, heuristic algorithms, such as the crossentropy algorithm, are most commonly adopted to calculate the numerical solutions [86].

\subsubsection{Closed-Form Solution Category}

To obtain closed-form solutions, researchers often need to highly abstract the problem and impose strict assumptions to develop structured models, which undoubtedly weakens their models' practicality. However, closed-form solutions have the strength of producing more analytical inferences to improve the current understanding of the main trade-offs and sharpen managers' intuition for decision-making. Specifically, all game theory models and newsvendor models seek to obtain closed-form solutions. On the one hand, researchers can analyze the properties of closed-form solutions and, based on this, draw a series of counterintuitive managerial recommendations $[49,66,77]$. On the other hand, by analyzing the sensitivity of the closed-form solutions to the parameters, the effectiveness of the model conclusion can be intuitively described $[9,14,75]$.

\subsubsection{Theoretical Solution Category}

One significant advantage of a theoretical summary is that it offers modeling principles and an analysis framework for researchers to explore newly emerging supply chain issues entailed by different taxes, such as the postponement strategy in CBSCs [50], and sup- 
ply chain design under the effect of new global factors, such as coronavirus and trade wars $[4,16]$. In addition, articles based on case studies tend to present a theoretical framework to improve the applicability of the results to specific tax regulations [72] and supply chain themes [6].

\section{Discussion}

\subsection{The Interface between CBSC Operations and Taxes}

As shown in Figure 7, this study constructs a conceptual framework to analyze the interface between the tax system and CBSC operations.

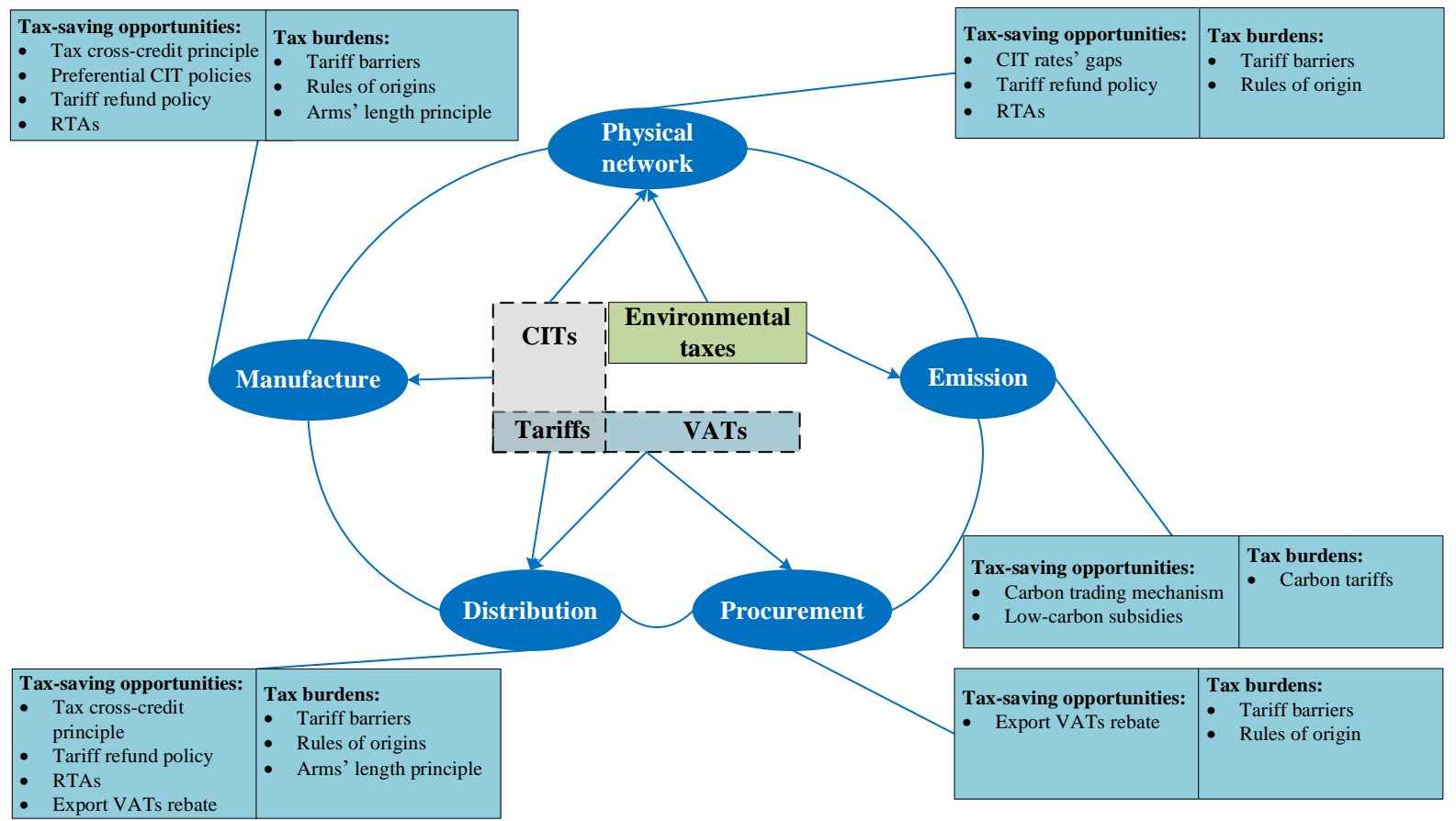

Figure 7. The interaction between CBSC operations and the tax system.

The taxes that significantly affect CBSC operations include tariffs, CIT, VAT, and environmental taxes. Among them, tariffs affect a CBSC's distribution decisions by changing the landed costs of cross-border products. In addition, the tariff uncertainty caused by trade frictions will make an MNF's manufacturing headquarters more inclined to adopt a localized production strategy to avoid tariff risk. In addition to tariffs, the CIT is also one of the major concerns for MNF capacity investment decisions. The difference in CIT rates across different countries and the CIT incentives in emerging countries, such as the countries along the Belt and Road, offer MNFs considerable tax-saving opportunities when formulating appropriate offshoring decisions.

In contrast to the impact of tariffs and CITs, the VAT, as a kind of turnover tax, has more complex impacts on CBSC decisions, which largely depend on the VAT collection and refund policies for cross-border transactions in different countries. Taking China's exportoriented VAT as an example, the government adopts the VAT regulation of "exemption, credit and refund" based on the exported goods' FOB price. The calculation of the VAT payable to the Chinese tax authority is as follows $[9,10]$ :

VAT payable to tax authority $=$ domestic sales $\times$ VAT rate $+($ export sales - cost of imported materials $)$

$$
\times(\text { VAT rate }- \text { VAT refund rate })-\text { input VAT }
$$

The Chinese government does not offer a zero export VAT rate, and the changes in the VAT refund rate will be magnified by multiplying export sales. Specifically, an increase in 
the VAT refund rate not only improves the revenue per product of Chinese exporters but also encourages MNFs to purchase more raw materials from China.

\subsection{The Evolution of Supply Chain Themes}

According to the content analysis in Section 3.4, the evolution of supply chain themes in the selected articles is presented (see Figure 8). It is apparent that the tax-related supply chain themes have tended to diversify since 2005.

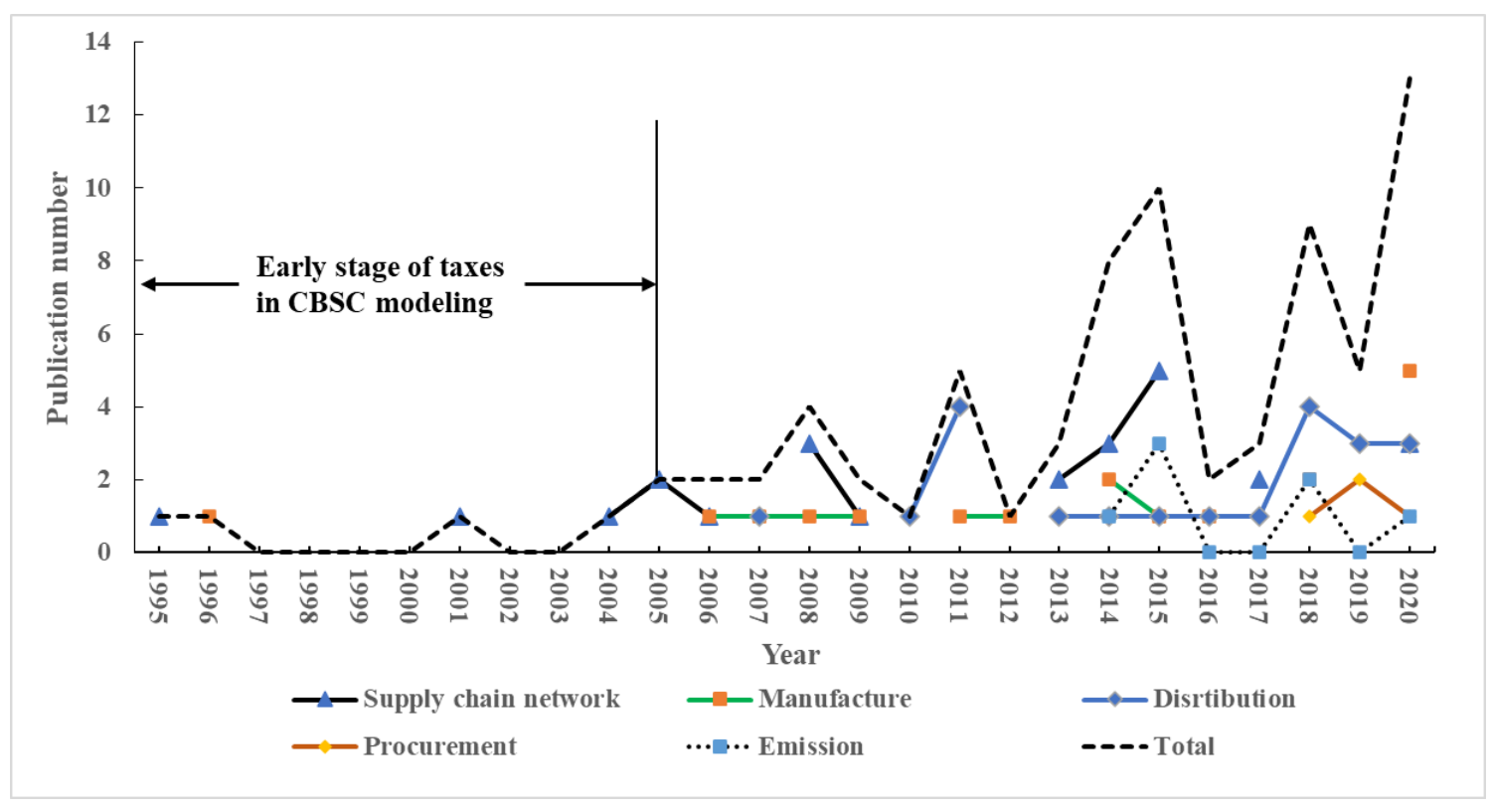

Figure 8. The evolution of supply chain themes over time.

Before 2005, researchers were mainly focused on the global supply chain network design problem. The corresponding decision-support models were based on mixed-integer programming models with the objective of maximizing global after-tax profit. Tax-related factors were treated as variable costs, which are proportional to freight volume or revenue. In this way, although tax costs were considered, they did not change the model structure of the typical CBSC network design problem [28,47,48]. Wilhelm et al. [25] improved the traditional CBSC network design models to cope with NAFTA's influence, and they were the first to study this problem, i.e., global supply chain network design considering a specific tariff policy.

From 2005 to the present, extensive research has focused on other operational decisions, in addition to supply chain network design, to cope with tax-related issues. The most apparent tax-saving opportunities come from the combination of distribution decisions, such as distribution channel structure, transfer pricing, and CIT gaps in different countries $[9,64,66]$. In addition, embedding the tax effects into manufacturing decisions such as production outsourcing strategy $[49,53,78]$ and procurement decisions [10] can also significantly reduce the tax costs in a CBSC.

Combining the results of Sections 3.2-3.4, the research methodologies applied in each supply chain theme are presented in Table 6. For the themes of the supply chain network, manufacture, and distribution, both quantitative and qualitative methodologies are applied to analyze the impacts of different taxes. However, qualitative methodologies, such as case studies and theoretical/literature reviews, are lacking for the themes of procurement and emissions. 
Table 6. Research methodologies for each supply chain theme.

\begin{tabular}{llllll}
\hline & Supply Chain Network & Manufacture & Distribution & Procurement & Emission \\
\hline MIP model & $\sqrt{ }$ & & $\sqrt{ }$ & & $\sqrt{ }$ \\
NLP model & $\sqrt{ }$ & $\sqrt{ }$ & $\sqrt{ }$ & $\sqrt{ }$ & $\sqrt{ }$ \\
$\begin{array}{l}\text { Game theory model } \\
\text { Newsvendor model }\end{array}$ & & $\sqrt{ }$ & $\sqrt{ }$ & $\sqrt{ }$ & \\
$\begin{array}{l}\text { Equilibrium model } \\
\text { MLP model }\end{array}$ & $\sqrt{ }$ & $\sqrt{ }$ & & \\
$\begin{array}{l}\text { Dynamic programming model } \\
\text { Deep learning }\end{array}$ & & $\sqrt{ }$ & & \\
$\begin{array}{l}\text { Structural equations model } \\
\text { Interpretive structural model }\end{array}$ & & & $\sqrt{ }$ & \\
$\begin{array}{l}\text { Questionnaire } \\
\text { surveys/Semi-structured }\end{array}$ & & & $\sqrt{ }$ & \\
interviews & & $\sqrt{ }$ & \\
$\begin{array}{l}\text { Case study } \\
\text { Theoretical/literature review }\end{array}$ & $\sqrt{ }$ & & & \\
$\begin{array}{l}\text { System dynamics model } \\
\text { Simulation experiment based on } \\
\text { discrete events }\end{array}$ & $\sqrt{ }$ & & & \\
\hline
\end{tabular}

\subsection{The Impacts of Different Taxes}

As presented in Section 3.4, the tax types investigated in the selected articles include CIT, tariffs, environmental taxes, and VAT. Furthermore, different types of taxes affect the operation of CBSCs in different ways.

As shown in Figure 9, environmental taxes and tariffs will directly affect the landed cost of markets in different jurisdictions and then change the production configuration along a global supply chain, which has been fully explained in the existing supply chain network design model. In addition to the function of production configuration, tariff costs could also affect an MNF's production outsourcing decision, and this impact may even outweigh the rising transportation cost and falling labor cost. For example, many MNFs located in developed economies, especially the USA, were considering reshoring overseas plants because of the rise of tariffs in their home countries.

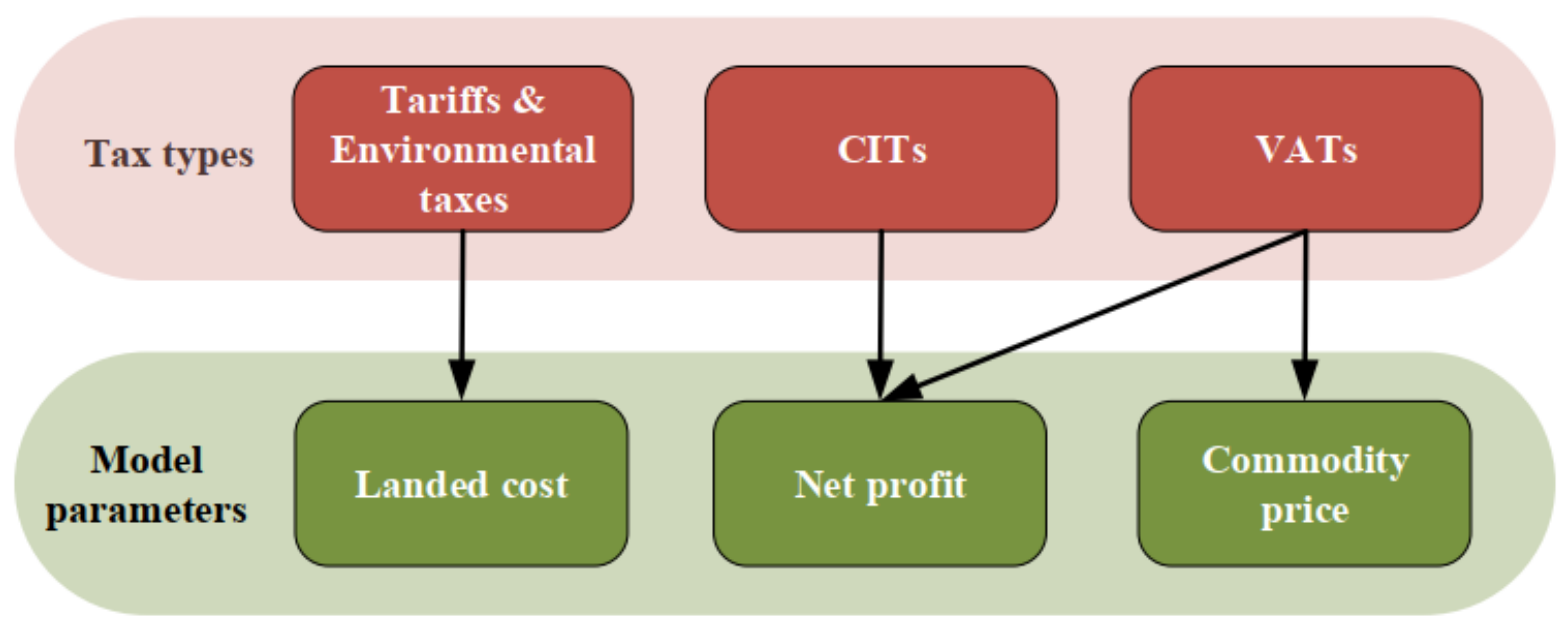

Figure 9. The impact of taxes on CBSC model parameters.

In many cases, the CIT alone may account for more than thirty percent of an MNF's total pretax income. Furthermore, MNFs tend to shift their taxable income from hightax to low-tax jurisdictions to exploit tax rate differentials [95]. In practice, managers can affect taxable income through transfer pricing, i.e., transactions between different 
divisions located in different jurisdictions. Although the price charged for the products is fully determined by the managers, it is still subject to different jurisdictional regulations. The interactions among the transfer price, tax rate differentials, and regulations in different jurisdictions make capacity decisions that consider the impact of transfer prices nontrivial.

The regulations concerning VATs mainly affect CBSC modeling in two aspects: commodity prices and firm net profit. For example, Hsu and Zhu [9] focused on China's export-oriented tax rules, i.e., export VAT rebate regulations. They found that China's export VAT rebate regulations will significantly affect supply chain organizational structures, i.e., reallocating at the final product level or at the imported component level and keeping a single bonded warehouse or two warehouses for bonded and unbonded inventories.

\subsection{New Trade-Offs}

Based on the summary of the selected articles and the observation of real cases, the new trade-offs that international taxes bring to CBSC operations are presented in this section.

The most significant trade-offs occur in the reverse relationship between preferential CIT policies and material acquisition costs. In general, emerging manufacturing countries adopt preferential CIT policies to attract MNFs' capacity investment; for example, countries along the Belt and Road have reduced or exempted the CIT of the first five years for MNFs that come to build factories there. However, these emerging manufacturing countries generally do not have a complete supply network, and MNFs building factories in these countries will inevitably lead to an increase in material acquisition costs.

In addition, an MNF's global procurement strategy and the increasingly strict rules of origin are other trade-offs in CBSC operations. In the current global trading environment, both developed and developing countries are committed to expanding the domestic portion of the global value chain and forming appropriate ROOs to achieve this goal. For example, due to the procurement of components from China, Caterpillar, a famous American machinery and equipment manufacturer, bears an additional cost of 250 million to 350 million US dollars due to high tariffs.

In addition to the above two trade-offs, the increasing tariff barriers bring additional trade-offs for MNFs' offshore production strategy. The offshore production mode plays an essential role in the world economy. MNFs such as Apple and IBM have established offshore partnerships with contract manufacturers around the world. On the one hand, by outsourcing production, MNFs can focus on product research and development; MNFs, as brand owners, can utilize the location advantages of offshore manufacturers to open up overseas markets while reducing unit production costs. However, with the increase in tariff barriers, the cost advantage of offshore production is no longer obvious.

\section{Research Opportunities}

\subsection{Modeling the Tax-Related Risks}

With the turmoil in the global economy, increasing trade frictions have increased the uncertainty of CBSC tax costs [4]. Taking tariffs as an example, in July 2018, the tariffs that took effect on the products traded between China and the US reached as much as 17 billion dollars, leading to a more than $25 \%$ increase in CBSC tariff costs for several industries, such as soybeans, steel, and automobiles.

Risk factors such as supply interruptions, exchange rate fluctuations, and demand uncertainty have already been effectively described by existing CBSC decision-making models, but the risks caused by changes in tax policies and tax rates have not been fully explored. To the best of our knowledge, only Dong and Kouvelis [61] embedded tariff uncertainty in CBSC modeling. However, their assumption of tariffs as a uniformly distributed random variable makes this model unapplicable in many situations. In reality, tax rates usually vary discretely between several fixed values; in this case, constructing a CBSC decision-making model that can reflect the characteristics of tariff changes is vital for guiding the commercial practice of MNFs. 


\subsection{Modifying Existing CBSC Models to Include Tax Conventions}

It is observed that a common communication platform between international tax planners and CBSC operations optimizers is lacking [6]. Specifically, international tax planners are mainly concerned with tax accounting conventions and collection efficiency. However, the current research related to CBSC optimization is too simplified to effectively describe tax effects. Multiplying corporate income by a fixed tax rate to calculate tax costs is commonly adopted by CBSC researchers. This oversimplified calculation method results in capital occupation costs due to tax reviews, and the time gap between input taxes and output taxes cannot be reflected. This makes current CBSC solutions intended to maximize after-tax profits uneconomical or even unfeasible in the eyes of international tax planners.

Therefore, CBSC optimizers should pay more attention to the changes that tax accounting conventions have brought to the existing model structure. The works of Hsu and $\mathrm{Hu}$ [14], Niu et al. [49] and Xu et al. [10] have made successful attempts in this direction and obtained a series of effective managerial insights.

\subsection{Exploring the Conflicts among Different Tax Types}

In reality, different types of taxes have conflicting impacts on CBSC decisions. For example, the CIT planning strategy of MNFs is often affected by tariff costs, especially in the current global business environment. In particular, decreased CIT costs from local tax incentives and increased tariff costs caused by cross-border distribution complicate MNFs' supply chain decisions, such as production outsourcing and the distribution channel structure. In addition, the VAT export refund policy is an effective method for a country to cope with changes in the foreign trade environment. Some countries, such as China, often actively adjust the export tax rebate rate to offset the impact of foreign trade changes [9].

Although several decision models related to the CBSC network design have simultaneously considered CIT and tariff costs, where the tariff costs are characterized as the product of the tariff rate and the value of the corresponding inbound and outbound goods and the CIT is the product of the company's total income and the CIT rate in specific countries [25,48], the conflicting impacts of different taxes have not been quantitatively explored.

\subsection{Modeling Different Tax Incentives in CBSC Operations}

Tax incentives mainly come from three aspects. First, local governments implement CIT reductions or refunds to attract foreign investment in specific industries, which are increasingly common in newly emerging manufacturing countries such as Vietnam [66]. Many MNFs, such as Tesla and Mercedes Benz, have benefitted greatly from tax incentivebased CBSC design [4]. The second is the tax incentives delivered by different RTAs. This kind of tax incentive is mainly through zero tariff rates and reductions (or refunds) in the tariffs paid on imports. However, it is not free, or even costly, for some countries to join the specific RTA and meet the corresponding rules of origin restrictions $[8,25]$. The third concerns the tax incentives from the home countries of MNFs. In the context of globalization, the interruption of any key supply chain node may have a direct impact on the overall performance of a CBSC. Specifically, the trade and travel restrictions adopted by some countries in response to COVID-19 has caused CBSCs to break, which has increased the concerns of many MNFs' home countries regarding excessive dependence on imports from a single country. Some countries, such as Japan, have implemented a series of tax incentives to support local MNFs in constructing alternative supply chain schemes or transferring part of their supply chain back to their home countries.

As different tax incentives will affect MNFs' performance in different ways, the interactions of these tax incentives and the comprehensive impact of these incentives on CBSC operations need to be taken into account in CBSC models. 


\subsection{Embedding Tax Policies in Cross-Border E-Commerce Models}

Under the influence of the COVID-19 epidemic, the consumption habits of global consumers have changed substantially. The small-volume and multi-category cross-border e-commerce trade mode is playing an increasingly prominent role in CBSC. Take China as an example, the import and export scale of cross-border e-commerce reached 1.69 trillion RMB in 2020, with an increase of $31.1 \%$. Furthermore, the cross-border e-commerce trading mode has become an important driving force for China's foreign trade to go up against the downward trend of the global economy.

As an emerging foreign trade pattern, there is a strong uncertainty in the import and export tax policy for cross-border e-commerce, which brings tax risks for the related enterprises. For example, since 2014, China's State Administration of Taxation has made nine important adjustments to the tax policies for cross-border e-commerce, bringing farreaching effects to the global cross-border e-commerce industry. In addition, according to our survey for several SMEs operating on AliExpress, a leading cross-border e-commerce platform, the tax costs and changes in tax policy are the most challenging issues faced by cross-border e-commerce enterprises.

Nevertheless, this review finds that the tax issues of cross-border e-commerce has been principally omitted by researchers in the CBSC operations. Only the research of Wang et al. [63] and Guo [50] considered the impact of specific tax costs, such as tariffs, on logistics mode and pricing decision of cross-border e-commerce enterprises. Therefore, embedding the impact of tax policies in the cross-border e-commerce model is necessary, and it will possess significant theoretical and practical significance for practitioners of cross-border e-commerce.

\section{Conclusions}

This paper presents a literature review on taxes in CBSC modeling based on content analysis. First, this paper constructed a systematic literature collection approach based on the string-based search and specific validation process, and 71 pertinent publications were identified as the selected articles for further content analysis. Then, a descriptive analysis related to the time and regional distribution of the selected publications was carried out in Section 3.1. Furthermore, a four-dimensional categorization, including the supply chain theme dimension, research methodology dimension, tax type dimension and illustration type dimension, was proposed to classify and summarize the research contents of the selected articles. Based on the four-dimensional categorization, the discussion of the key issues, i.e., the tax-saving opportunities, evolution of supply chain themes, impact of different taxes and new trade-offs, were addressed in Section 4 . The research opportunities on this topic were presented in Section 5.

Focusing on the research questions raised in Section 1, this paper presents the following main findings: (1) Tax impacts are attracting increasing attention from CBSC researchers, and research on the interface between tax planning and supply chain optimization remains at an early stage. (2) The supply chain themes that are affected by tax-related issues in CBSC operations are diverse, including supply chain network design, distribution channel structure, product quantity and quality, production outsourcing, procurement mode and supply chain emissions. (3) Four kinds of mainstream methodologies, i.e., mathematical models, empirical models, conceptual models and simulation models, have been applied to explore the tax effects in CBSC modeling, and three illustration types have been adopted to illustrate the corresponding managerial insights. (4) There are four main types of taxes that have significant impacts on CBSC operations, i.e., CITs, tariffs, environmental taxes and VATs. (5) The tax-saving opportunities in CBSC operations mainly come from five aspects: CIT rate gaps in different regions, special tax regulations such as the tax cross-credit principle and arm's length principle, RTAs, preferential tax policies and export VAT rebate policies.

To the best of our knowledge, this study is the first literature review that explores the impact of taxes from the perspective of CBSC modeling. This review is timely because 
it provides a common communication platform for tax planners and CBSC optimizers in the current global business environment in which the impact of taxes on CBSC operations is increasingly prominent. This study makes a twofold contribution. For academia, this research provides a framework to analyze the trade-offs between taxes and traditional CBSC modeling factors, and future research opportunities are provided for CBSC scholars. For industry, this research provides a series of tax-saving opportunities that are effective in assisting MNFs in making CBSC decisions to cope with the upheavals of the current global economy.

Nevertheless, this work has a limitation that must be discussed: a small sample size. Although tax issues have been extensively investigated in the areas of economics and finance, related research in the field of CBSC operations remains limited. Thus, although the authors of this paper have made considerable effort to prevent omissions in the search process, only 71 articles remained in the final sample group. In addition, this study focuses on academic research related to CBSC operation and management. At the same time, the practical materials on taxation, such as tax regulations, legal frameworks, international taxation agreements, and articles published in professional publications, are not covered in this review, making this study flawed in practical terms.

Supplementary Materials: The following are available online at https:/ /www.mdpi.com/article/10 $.3390 /$ jtaer17010002/s1. S1 presents the regional distribution of the selected publications. S2 shows the journal distribution of the selected publications. S3 introduces the top-cited publications in the sample. S4 indicates the most influential authors of the selected publications.

Author Contributions: Conceptualization, D.M. and H.R.; methodology, C.W.; software, H.R.; validation, D.M. and C.W.; formal analysis, D.M. and H.R.; investigation, H.R.; resources, H.R.; data curation, H.R.; writing —original draft preparation, H.R.; writing—review and editing, D.M.; visualization, H.R.; supervision, C.W.; project administration, D.M.; funding acquisition, D.M. All authors have read and agreed to the published version of the manuscript.

Funding: This research was funded by the Fundamental Research Funds for the Central Universities (2020YJS052) and the National Natural Science Foundation of China (72172012, 72071006, and 62073007).

Acknowledgments: This paper is supported by the Fundamental Research Funds for the Central Universities and the National Natural Science Foundation of China.

Conflicts of Interest: No potential conflict of interest was reported by the authors.

\section{References}

1. Durbhakula, V.K.; Kim, D.J. E-business for Nations: A Study of National Level Ebusiness Adoption Factors Using Country Characteristics-Business-Technology-Government Framework. J. Theor. Appl. Electron. Commer. Res. 2011, 6, 1-12. [CrossRef]

2. Knol, A.; Tan, Y.H. The Cultivation of Information Infrastructures for International Trade: Stakeholder Challenges and Engagement Reasons. J. Theor. Appl. Electron. Commer. Res. 2018, 13, 106-117. [CrossRef]

3. Navaretti, G.B.; Venables, A.J. Multinational Firms in the World Economy; Princeton University Press: Princeton, NJ, USA, 2020.

4. Cohen, M.A.; Lee, H.L. Designing the right global supply chain network. MSOM-Manuf. Serv. Oper. Manag. 2020, 22, 15-24. [CrossRef]

5. Cerrillo, R.A.; Rodriguez, M.G.L. Tax Implications of Selling Electronic Books in the European Union. J. Theor. Appl. Electron. Commer. Res. 2016, 11, 28-40. [CrossRef]

6. Henkow, O.; Norrman, A. Tax aligned global supply chains: Environmental impact illustrations, legal reflections and crossfunctional flow charts. Int. J. Phys. Distrib. Logist. Manag. 2011, 41, 878-895. [CrossRef]

7. Stef van Weeghel, A.P.; Dane, T.; Ramalho, R.; Croci, S.; Nasr, J. Paying Taxes 2020; PwC, the World Bank and International Finance Corporation: Washington, NY, USA, 2020; pp. 1-11.

8. Feng, C.M.; Wu, P.J. A tax savings model for the emerging global manufacturing network. Int. J. Prod. Econ. 2009, 122, 534-546. [CrossRef]

9. Hsu, V.N.; Zhu, K.J. Tax-effective supply chain decisions under China's export-oriented tax policies. MSOM-Manuf. Serv. Oper. Manag. 2011, 13, 163-179. [CrossRef]

10. Xu, J.Y.; Hsu, V.N.; Niu, B.Z. The impacts of markets and tax on a multinational firm's procurement strategy in China. Prod. Oper. Manag. 2018, 27, 251-264. [CrossRef]

11. WTO. Regional Trade Agreements; World Trade Organization: Geneva, Switzerland, 2020. 
12. Singh, S.; Haldar, N.; Bhattacharya, A. Offshore manufacturing contract design based on transfer price considering green tax: A bilevel programming approach. Int. J. Prod. Res. 2018, 56, 1825-1849. [CrossRef]

13. Schenker, O.; Koesler, S.; Löschel, A. On the effects of unilateral environmental policy on offshoring in multi-stage production processes. Can. J. Econ. 2018, 51, 1221-1256. [CrossRef]

14. Hsu, V.; Hu, Q.H. Global sourcing decisions for a multinational firm with foreign tax credit planning. IISE Trans. $2020,52,688-702$. [CrossRef]

15. Hammami, R.; Frein, Y. Integration of the profit-split transfer pricing method in the design of global supply chains with a focus on offshoring context. Comput. Ind. Eng. 2014, 76, 243-252. [CrossRef]

16. Handfield, R.B.; Graham, G.; Burns, L. Corona virus, tariffs, trade wars and supply chain evolutionary design. Int. J. Oper. Prod. Manag. 2020, 40, 1649-1660. [CrossRef]

17. Baldenius, T.; Reichelstein, S. External and internal pricing in multidivisional firms. J. Account. Res. 2006, 44, 1-28. [CrossRef]

18. Baldenius, T.; Melumad, N.D.; Reichelstein, S. Integrating managerial and tax objectives in transfer pricing. Account. Rev. 2004, 79, 591-615. [CrossRef]

19. Pfeiffer, T.; Schiller, U.; Wagner, J. Cost-based transfer pricing. Rev. Account. Stud. 2011, 16, 219-246. [CrossRef]

20. Mayring, P. Qualitative content analysis. A Companion Qual. Res. 2004, 1, 159-176.

21. Van Mieghem, J.A. Commissioned paper: Capacity management, investment, and hedging: Review and recent developments. Manuf. Serv. Oper. Manag. 2003, 5, 269-302. [CrossRef]

22. Snyder, L.V.; Shen, Z.J.M. Introduction. In Fundamentals of Supply Chain Theory; John Wiley \& Sons: Hoboken, NJ, USA, 2019; pp. $1-4$.

23. Ghadimi, P.; Wang, C.; Lim, M.K. Sustainable supply chain modeling and analysis: Past debate, present problems and future challenges. Resour. Conserv. Recycl. 2019, 140, 72-84. [CrossRef]

24. Meixell, M.J.; Waller, M.; Norbis, M. A review of the transportation mode choice and carrier selection literature. Int. J. Logist. Manag. 2008, 19, 183-211. [CrossRef]

25. Wilhelm, W.; Liang, D.; Rao, B.J.; Warrier, D.; Zhu, X.Y.; Bulusu, S. Design of international assembly systems and their supply chains under NAFTA. Transp. Res. Part E Logist. Transp. Rev. 2005, 41, 467-493. [CrossRef]

26. Rebs, T.; Brandenburg, M.; Seuring, S. System dynamics modeling for sustainable supply chain management: A literature review and systems thinking approach. J. Clean. Prod. 2019, 208, 1265-1280. [CrossRef]

27. Cronbach, L.J. Coefficient alpha and the internal structure of tests. Psychometrika 1951, 16, 297-334. [CrossRef]

28. Arntzen, B.C.; Brown, G.G.; Harrison, T.P.; Trafton, L.L. Global supply chain management at Digital Equipment Corporation. Interfaces 1995, 25, 69-93. [CrossRef]

29. Prataviera, L.B.; Norrman, A.; Melacini, M. Global distribution network design: Exploration of facility location driven by tax considerations and related cross-country implications. Int. J. Logist.-Res. Appl. 2020, 1-24. [CrossRef]

30. Sabet, E.; Yazdani, B.; Kian, R.; Galanakis, K. A strategic and global manufacturing capacity management optimisation model: A Scenario-based multi-stage stochastic programming approach. Omega-Int. J. Manag. Sci. 2020, 93, 1-20. [CrossRef]

31. Mariel, K.; Minner, S. Benders decomposition for a strategic network design problem under NAFTA local content requirements. Omega-Int. J. Manag. Sci. 2017, 68, 62-75. [CrossRef]

32. Urata, T.; Yamada, T.; Itsubo, N.; Inoue, M. Global Supply Chain Network Design and Asian Analysis with Material-Based Carbon Emissions and Tax. Comput. Ind. Eng. 2017, 113. [CrossRef]

33. de Matta, R.; Miller, T. Formation of a strategic manufacturing and distribution network with transfer prices. Eur. J. Oper. Res. 2015, 241, 435-448. [CrossRef]

34. Fernandes, R.; Pinho, C.; Gouveia, B. Supply chain networks design and transfer-pricing. Int. J. Logist. Manag. 2015, 26, 128-146. [CrossRef]

35. Hasani, A.; Zegordi, S.H.; Nikbakhsh, E. Robust closed-loop global supply chain network design under uncertainty: The case of the medical device industry. Int. J. Prod. Res. 2015, 53, 1596-1624. [CrossRef]

36. Mariel, K.; Minner, S. Strategic capacity planning in automotive production networks under duties and duty drawbacks. Int. J. Prod. Econ. 2015, 170, 687-700. [CrossRef]

37. Zhou, Y.; Gong, D.C.; Huang, B.; Peters, B.A. The Impacts of Carbon Tariff on Green Supply Chain Design. IEEE Trans. Autom. Sci. Eng. 2015, 14, 1542-1555. [CrossRef]

38. Hamad, R.; Gualda, N.D.F. Global Sourcing Approach to Improve Cash Flow of Agribusiness Companies in Brazil. Interfaces 2014, 44, 317-327. [CrossRef]

39. Hammami, R.; Frein, Y. Redesign of global supply chains with integration of transfer pricing: Mathematical modeling and managerial insights. Int. J. Prod. Econ. 2014, 158, 267-277. [CrossRef]

40. Bassett, M.; Gardner, L. Designing optimal global supply chains at Dow AgroSciences. Ann. Oper. Res. 2013, 203, 187-216. [CrossRef]

41. Fahimnia, B.; Parkinson, E.; Rachaniotis, N.P.; Mohamed, Z.; Goh, M. Supply chain planning for a multinational enterprise: A performance analysis case study. Int. J. Logist.-Res. Appl. 2013, 16, 349-366. [CrossRef]

42. Hamad, R.; Gualda, N.D.F. Model for facilities or vendors location in a global scale considering several echelons in the Chain. Netw. Spat. Econ. 2008, 8, 297-307. [CrossRef] 
43. Miller, T.; de Matta, R. A global supply chain profit maximization and transfer pricing model. J. Bus. Logist. 2008, 29, 175-199. [CrossRef]

44. Tsiakis, P.; Papageorgiou, L.G. Optimal production allocation and distribution supply chain networks. Int. J. Prod. Econ. 2008, 111, 468-483. [CrossRef]

45. Vila, D.; Martel, A.; Beauregard, R. Designing logistics networks in divergent process industries: A methodology and its application to the lumber industry. Int. J. Prod. Econ. 2006, 102, 358-378. [CrossRef]

46. Chakravarty, A.K. Global plant capacity and product allocation with pricing decisions-Production, manufacturing and logistics. Eur. J. Oper. Res. 2005, 165, 157-181. [CrossRef]

47. Fandel, G.; Stammen, M. A general model for extended strategic supply chain management with emphasis on product life cycles including development and recycling. Int. J. Prod. Econ. 2004, 89, 293-308. [CrossRef]

48. Vidal, C.J.; Goetschalckx, M. A global supply chain model with transfer pricing and transportation cost allocation. Eur. J. Oper. Res. 2001, 129, 134-158. [CrossRef]

49. Niu, B.Z.; Li, Q.Y.; Liu, Y.Q. Conflict management in a multinational firm's production shifting decisions. Int. J. Prod. Econ. 2020, 230, 107880. [CrossRef] [PubMed]

50. Prataviera, L.B.; Perotti, S.; Melacini, M.; Moretti, E. Postponement strategies for global downstream supply chains: A conceptual framework. J. Bus. Logist. 2020, 41, 94-110. [CrossRef]

51. Turken, N.; Carrillo, J.; Verter, V. Strategic supply chain decisions under environmental regulations: When to invest in end-of-pipe and green technology. Eur. J. Oper. Res. 2020, 283, 601-613. [CrossRef]

52. Lu, X.Y.; Wu, Z.Q. How taxes impact bank and trade financing for Multinational Firms. Eur. J. Oper. Res. 2020, $286,218-232$. [CrossRef]

53. Xiao, W.Q.; Hsu, V.N.; Hu, Q.H. Manufacturing capacity decisions with demand uncertainty and tax cross-crediting. MSOMManuf. Serv. Oper. Manag. 2015, 17, 384-398. [CrossRef]

54. Choi, K.; Narasimhan, R.; Kim, S.W. Postponement strategy for international transfer of products in a global supply chain: A system dynamics examination. J. Oper. Manag. 2012, 30, 167-179. [CrossRef]

55. Bogataj, D.; Bogataj, M. The role of free economic zones in global supply chains-a case of reverse logistics. Int. J. Prod. Econ. 2011, 131, 365-371. [CrossRef]

56. Hameri, A.P.; Hintsa, J. Assessing the drivers of change for cross-border supply chains. Int. J. Phys. Distrib. Logist. Manag. 2009, 39, 741-761. [CrossRef]

57. Lu, C.S.; Liao, C.H.; Yang, C.C. Segmenting manufacturers' investment incentive preferences for international logistics zones. Int. J. Oper. Prod. Manag. 2008, 28, 106-129. [CrossRef]

58. Kazmer, D.; Roser, C. Analysis of design for global manufacturing guidelines. In Proceedings of the ASME 2007 International Design Engineering Technical Conferences and Computers and Information in Engineering Conference, Las Vegas, NV, USA, 4-7 September 2007.

59. Lu, C.S.; Yang, C.C. Comparison of investment preferences for international logistics zones in Kaohsiung, Hong Kong, and Shanghai ports from a Taiwanese manufacturer's perspective. Transp. J. 2006, 45, 30-51.

60. Huchzermeier, A.; Cohen, M.A. Valuing operational flexibility under exchange rate risk. Oper. Res. 1996, 44, 100-113. [CrossRef]

61. Dong, L.X.; Kouvelis, P. Impact of tariffs on global supply chain network configuration: Models, predictions, and future research. MSOM-Manuf. Serv. Oper. Manag. 2020, 22, 25-35. [CrossRef]

62. Gao, L.; Zhao, X. Determining intra-company transfer pricing for multinational corporations. Int. J. Prod. Econ. 2015, 168, 340-350. [CrossRef]

63. Wang, X.H.; Xie, J.C.; Fan, Z.P. B2C cross-border E-commerce logistics mode selection considering product returns. Int. J. Prod. Res. 2021, 59, 3841-3860. [CrossRef]

64. Nagurney, A.; Besik, D.; Nagurney, L.S. Global supply chain networks and tariff rate quotas: Equilibrium analysis with application to agricultural products. J. Glob. Optim. 2019, 75, 439-460. [CrossRef]

65. Niu, B.Z.; Liu, Y.Q.; Liu, F.; Lee, C.K.M. Transfer pricing and channel structure of a multinational firm under overseas retail disruption risk. Int. J. Prod. Res. 2019, 57, 2901-2925. [CrossRef]

66. Niu, B.Z.; Xu, J.W.; Lee, C.K.M.; Chen, L. Order timing and tax planning when selling to a rival in a low-tax emerging market. Transp. Res. Part E Logist. Transp. Rev. 2019, 123, 165-179. [CrossRef]

67. Kim, B.; Park, K.S.; Jung, S.Y.; Park, S.H. Offshoring and outsourcing in a global supply chain: Impact of the arm's length regulation on transfer pricing. Eur. J. Oper. Res. 2018, 266, 88-98. [CrossRef]

68. Wu, Z.Q.; Lu, X.Y. The effect of transfer pricing strategies on optimal control policies for a tax-efficient supply chain. Omega-Int. J. Manag. Sci. 2018, 80, 209-219. [CrossRef]

69. Zhang, X.B.; Huang, S.; Wan, Z. Stochastic programming approach to global supply chain management under random additive demand. Oper. Res. 2018, 18, 389-420. [CrossRef]

70. Shunko, M.; Do, H.T.; Tsay, A.A. Supply chain strategies and international tax arbitrage. Prod. Oper. Manag. 2017, 26, 231-251. [CrossRef]

71. Huh, W.T.; Park, K.S. Impact of transfer pricing methods for tax purposes on supply chain performance under demand uncertainty. Nav. Res. Logist. 2013, 60, 269-293. [CrossRef] 
72. Kumar, S.; Sosnoski, M. Decision framework for the analysis and selection of appropriate transfer pricing for a resilient global SME manufacturing operation-A business case. Int. J. Prod. Res. 2011, 49, 5431-5448. [CrossRef]

73. Matsui, K. Intrafirm trade, arm's-length transfer pricing rule, and coordination failure. Eur. J. Oper. Res. 2011, 212, 570-582. [CrossRef]

74. Perron, S.; Hansen, P.; Le Digabel, S.; Mladenovic, N. Exact and heuristic solutions of the global supply chain problem with transfer pricing. Eur. J. Oper. Res. 2010, 202, 864-879. [CrossRef]

75. Shunko, M.; Gavirneni, S. Role of transfer prices in global supply chains with random demands. J. Ind. Manag. Optim. 2007, 3, 99-117. [CrossRef]

76. Cui, S.L.; Lu, L.X. Optimizing local content requirements under technology gaps. MSOM-Manuf. Serv. Oper. Manag. 2019, 21, 213-230. [CrossRef]

77. Niu, B.Z.; Mu, Z.H.; Chen, K.L. Quality spillover, tariff, and multinational firms' local sourcing strategies. Int. Trans. Oper. Res. 2019, 26, 2508-2530. [CrossRef]

78. Fang, Y.; Yu, Y.G.; Shi, Y.; Liu, J. The effect of carbon tariffs on global emission control: A global supply chain model. Transp. Res. Part E Logist. Transp. Rev. 2020, 133, 101818. [CrossRef]

79. Micheli, G.J.L.; Mantella, F. Modelling an environmentally-extended inventory routing problem with demand uncertainty and a heterogeneous fleet under carbon control policies. Int. J. Prod. Econ. 2018, 204, 316-327. [CrossRef]

80. Bonilla, D.; Keller, H.; Schmiele, J. Climate policy and solutions for green supply chains: Europe's predicament. Supply Chain Manag. 2015, 20, 249-263. [CrossRef]

81. Fahimnia, B.; Sarkis, J.; Choudhary, A.; Eshragh, A. Tactical supply chain planning under a carbon tax policy scheme: A case study. Int. J. Prod. Econ. 2015, 164, 206-215. [CrossRef]

82. Hammami, R.; Nouira, I.; Frein, Y. Carbon emissions in a multi-echelon production-inventory model with lead time constraints. Int. J. Prod. Econ. 2015, 164, 292-307. [CrossRef]

83. Soysal, M.; Bloemhof-Ruwaard, J.M.; van der Vorst, J. Modelling food logistics networks with emission considerations: The case of an international beef supply chain. Int. J. Prod. Econ. 2014, 152, 57-70. [CrossRef]

84. Masha Shunko, L.D.; Gavirneni, S. Transfer pricing and sourcing strategies for multinational firms. Prod. Oper. Manag. 2014, 23, 2043-2057. [CrossRef]

85. Wang, Z.P.; Gao, W.L.; Mukhopadhyay, S.K. Impact of taxation on international transfer pricing and offshoring decisions. Ann. Oper. Res. 2016, 240, 683-707. [CrossRef]

86. Zhen, L. A three-stage optimization model for production and outsourcing under China's export-oriented tax policies. Transp. Res. Part E Logist. Transp. Rev. 2014, 69, 1-20. [CrossRef]

87. Allevi, E.; Gnudi, A.; Konnov, I.V.; Oggioni, G. Evaluating the effects of environmental regulations on a closed-loop supply chain network: A variational inequality approach. Ann. Oper. Res. 2018, 261, 1-43. [CrossRef]

88. Cohen, M.; Lee, H. Resource deployment analysis of global manufacturing and distribution network. J. Manuf. Oper. Manag. 1989, 2,81-104.

89. Reddy, K.N.; Kumar, A.; Sarkis, J.; Tiwari, M.K. Effect of carbon tax on reverse logistics network design. Comput. Ind. Eng. 2020, 139, 106184. [CrossRef]

90. Dou, G.W.; Cao, K.Y. A joint analysis of environmental and economic performances of closed-loop supply chains under carbon tax regulation. Comput. Ind. Eng. 2020, 146, 106624. [CrossRef]

91. Madani, S.R.; Rasti-Barzoki, M. Sustainable supply chain management with pricing, greening and governmental tariffs determining strategies: A game-theoretic approach. Comput. Ind. Eng. 2017, 105, 287-298. [CrossRef]

92. Gao, J.Z.; Xiao, Z.D.; Wei, H.X.; Zhou, G.H. Dual-channel green supply chain management with eco-label policy: A perspective of two types of green products. Comput. Ind. Eng. 2020, 146, 106613. [CrossRef]

93. Guo, L. Cross-border e-commerce platform for commodity automatic pricing model based on deep learning. Electron. Commer. Res. 2020. [CrossRef]

94. Du, J.; Sun, Y.; Ren, H. The relationship of delivery frequency with the cost and resource operational efficiency: A case study of jingdong logistics. Math. Comput. Sci. 2018, 3, 129-140.

95. Drtina, R.; Correa, H.L. How transfer prices can affect a supply chain strategic decision. Int. J. Logist. Syst. Manag. 2011, 8, 363-376. [CrossRef] 